\title{
Growth Cone Choices of Drosophila Motoneurons in Response to Muscle Fiber Mismatch
}

\author{
Akira Chiba, Huey Hing, Sydney Cash, ${ }^{a}$ and Haig Keshishian \\ Department of Biology, Yale University, New Haven, Connecticut 06511
}

In Drosophila embryos, each motoneuron is accurately matched to one or more singly identifiable muscle fibers. In this article we altered the number and pattern of the embryonic muscle fibers using genetic, heat shock, and laser ablation methods to test whether motoneuron growth cones are able to recognize specific targets. The choices made by two motoneurons were assayed using both Intracellular dye fills and immunocytochemistry. The motoneurons RP1 and RP3 have nearly identical central and peripheral axonal trajectories. However, RP3 innervates the two most ventral Iongitudinal muscle fibers, 7 and 6, while RP1 grows past these fibers to innervate only muscle fiber 13 . In rhomboid mutants muscle fiber 7 does not develop. Despite the loss of one of its targets, RP3 faithfully innervated the remaining muscle fiber 6 in over $80 \%$ of the observed cases. Furthermore, neuron RP1 accurately innervated muscle fiber 13, although it traversed one fiber fewer to reach it. Laser ablation of muscle fiber 7 confirmed the target choices shown by the motoneurons. In numb mutants, multiple muscle fibers, including 7,13 , and 12 , fail to develop. This allowed us to test whether fibers distal to the target are involved in muscle fiber recognition, possibly by halting the growth cone advance. In mutant embryos, RP3 innervated muscle fiber 6 at the same frequency regardless of the absence of the distal muscle fiber 13. By contrast, RP1, which had lost its target entirely, frequently failed to innervate any muscle fiber during the period examined. Finally, muscle fiber 13 can be duplicated in wild-type embryos by means of a brief heat pulse during myogenesis. Presented with two targets, RP1 innervated both fibers in each case examined, while RP3 synapsed with muscle fibers 7 and 6 normally. Neuron-specific antibodies revealed that the embryonic growth cone choices were not transient, but persisted into the larval neuromuscular projections. These results indicate that each motoneuron growth cone has a primary target preference, which is retained even when the numbers of the muscle fibers, and therefore their relative positions, are altered. We therefore suggest that synaptic recognition by Drosophila motoneuron

\footnotetext{
Received June 26, 1992; revised Aug. 10, 1992; accepted Aug. 14, 1992.

We thank Dr. R. Wyman for comments on the manuscript, Dr. M. Halpern for advice on the dye injection technique, and T.-N. Chang, M. Halfon, B. Harkins, J. Jarecki, and Dr. L.-S. Wang for critical advice during the course of the study. We also thank Drs. S. Benzer, C. Goodman, C. Hashimoto, and P. Taghert for antibody probes, and Dr. L. Jan for the numb and rhomboid stocks. This work was supported by grants from the NIH and March of Dimes Birth Defects Foundation to H.K.

Correspondence should be addressed to Akira Chiba, Department of Biology, Yale University, P.O. Box 6666, New Haven, CT 06511.

aPresent address: Columbia University School of Medicine, New York, NY 10032 .

Copyright (C) 1993 Society for Neuroscience $0270-6474 / 93 / 130714-19 \$ 05.00 / 0$
}

growth cones relies on unique features of the individual muscle fibers.

[Key words: cell recognition, Drosophila, growth cone, laser ablation, neuromuscular junction, numb, rhomboid, synaptic specificity, target mismatch]

One of the goals of developmental neurobiology is to understand how embryonic neurons select their synaptic partners. There is good evidence that the guidance cues used by growth cones often derive from the immediate cellular environment. Where individual choices were assessed using singly identified neurons, specific filopodial contacts have been found to play important roles in steering growth cones along their central and peripheral pathways (Palka et al., 1983; Raper et al., 1983; Bastiani et al., 1985; Grenningloh et al., 1991; Bentley and O'Connor, 1992; Bernhardt et al., 1992; Eisen and Pike, 1992). Dynamically expressed cell-surface molecules have been identified on both developing neurons and muscle fibers, and their role in regulating growth cone guidance and target recognition is a focus of extensive analyses in both vertebrate and invertebrate systems (Dodd and Jessell, 1988; Goodman et al., 1992; Landmesser, 1992; Schachner, 1992; Tosney, 1992).

Mismatch and translocation experiments have shown that vertebrate motoneurons have preferred muscle targets. In zebrafish embryos, each of the primary motoneurons becomes committed to its characteristic trajectory a few hours prior to the initiation of axon outgrowth. Also, primary motoneurons grow to the appropriate axial musculature despite translocation (Eisen, 1991; Eisen and Pike, 1992). In the chick embryo, translocation of motoneuron pools by spinal cord reversal or rearrangement of limb bud segments shows that motoneurons project accurately to their appropriate targets despite initially aberrant pathfinding (Lance-Jones and Landmesser, 1981; Whitelaw and Hollyday, 1983a,b; Landmesser, 1992).

The innervation of the Drosophila body wall is well suited for testing hypotheses about synaptic recognition during development. In this system, neuromuscular synapse formation can be examined in vivo with single-cell resolution. The embryonic and larval abdominal musculature consists of a simple, segmentally repeated array of 30 muscle fibers (Johansen et al., 1989a). Each multinuclcated muscle fiber can be individually identified by virtue of its attachment sites, orientation, and shape (Crossley, 1978; Anderson et al., 1988; Johansen et al., 1989a,b; Bate, 1990), as well as by characteristic molecular expression patterns (Halpern et al., 1991; Harkins and Keshishian, 1991; Nose and Goodman, 1991; Halfon et al., 1992; Harkins et al., 1992; Nose et al., 1992). At least 30 motoneurons innervate the muscle fibers in each hemisegment (Sink and Whitington, 1991a), over a dozen of which have been uniquely identified (Halpern 
et al., 1991; Sink and Whitington, 1991a; Cash et al., 1992; Keshishian et al., 1993).

During the last third of embryogenesis, the motoneurons exit the CNS in each hemisegment via two principal nerves (Johansen et al., 1989b). The resultant connectivity is accurate, with each motoneuron matched to one or more specific muscle fibers (Halpern et al., 1991; Sink and Whitington, 1991a,b; Cash et al., 1992). Furthermore, the behavior of growth cone target selection has been analyzed in detail for the Drosophila embryonic RP neurons (Halpern et al., 1991; Sink and Whitington, $1991 b)$. These studies suggest that specific growth cone choices are responsible for the observed accuracy of synaptic connections.

The cell bodies of the RP motoneurons (Fig. 1) lie adjacent to each other in the dorsal CNS (Jacobs and Goodman, 1989; Halpern et al., 1991). The axons project through essentially the same cellular environment within the CNS and exit via a common nerve [segmental nerve branch $b(\mathrm{SNb})]$ in the periphery. As the filopodia of efferent growth cones can sample widely in the body wall, it is likely that both neurons contact many of the same muscle fibers in the vicinity of their synaptic targets (Chiba et al., 1990; Halpern et al., 1991; Sink and Whitington, 1991b). However, despite the similarity of their trajectories, when the two neurons approach their respective targets they show distinct behaviors (Halpern et al., 1991; Sink and Whitington, 1991b). The RP3 growth cone advances between the external and internal muscle fiber layers, turning at the cleft between the two most proximal longitudinal muscle fibers 7 and 6 (Fig. $1 B$, arrow). There, the growth cone projects onto the fibers' internally facing surfaces. By contrast, the RP1 growth cone extends past muscle fibers 7 and 6 to innervate the internally facing surface of muscle fiber 13 (Fig. 1B).

In this article we have tested the hypothesis that motoneuron growth cones can distinguish between individual muscle fibers by challenging RP1 and RP3 with altered arrays of putative target cells. We altered both the number and pattern of the longitudinal muscle fibers in the embryo prior to their innervation. The resulting choices of the two RP growth cones were examined using both dye fills and immunocytochemistry. Here we describe three complementary situations: (1) the deletion of muscle fiber 7, one of the two normal targets of RP3; (2) the further deletion of muscle fiber 13, the sole normal target of RP1; and (3) the creation of an extra muscle fiber 13, duplicating RP1's target.

These mismatch experiments showed that the RP motoneurons projected to their normal targets despite alterations in the number and pattern of adjacent muscle fibers. We also found that, when their targets were either duplicated or halved in number, the innervating motoneurons accommodated these changes without significant targeting errors. Therefore, these results suggest that Drosophila motoneurons have preferred synaptic partners, and that target recognition depends on specific growth cone choices.

Some of the results in this article have been presented in abstract form (Chiba and Keshishian, 1991).

\section{Materials and Methods}

Fly strains. Wild-type Canton S (CS-5; Woodard et al., 1989) Drosophila melanogaster was used throughout the study. The mutants used were rhomboid ${ }^{\text {lacl }}\left(=\right.$ veinlet $\left.^{5}\right)$, generated by $\mathrm{P}$ element-insertional mutagenesis (Bier et al., 1989, 1990), and the numb $^{l}$ allele, first isolated as $l(2) n^{\prime} o^{7}$ by Cooley et al. (1988) and subsequently characterized by Uemura et al. (1989).

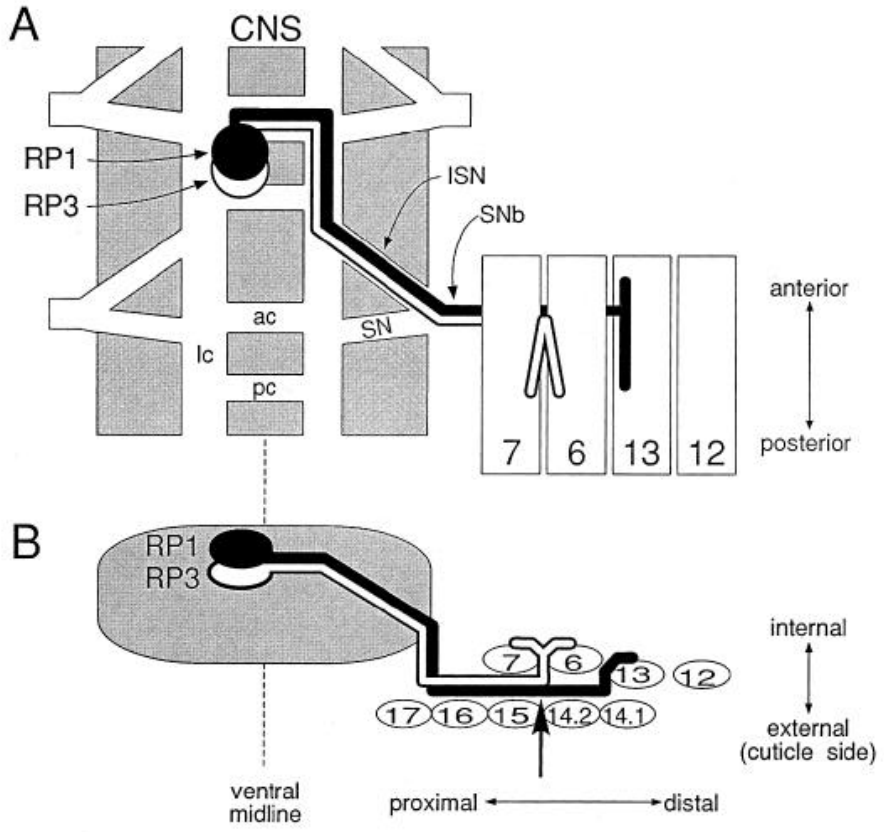

Figure 1. A schematic representation of the RP1 and RP3 motoneurons and their target muscle fibers in Drosophila embryos. A, Dorsal view showing two abdominal CNS segments (light gray area) alongside the ventral longitudinal muscle fibers $7,6,13$, and 12 (rectangles) in a right body-wall hemisegment. Anterior is to the top. The RP1 and RP3 trajectories and their synaptic targets are based on both previous studies (Jacobs and Goodman, 1989; Halpern et al., 1991; Sink and Whitington, 1991a) and this article. The cell bodies of both RP1 and RP3 lie within the space surrounded by the anterior and posterior commissures ( $a \mathrm{c}$ and $p c$ ) and the right and left longitudinal connectives $(l c)$. In this figure the contralateral RP1 and RP3 neurons are not shown. The axons cross the midline of the CNS within the anterior commissure. Turning posteriorly at the contralateral longitudinal connective, both axons extend posteriorly to exit the CNS via the intersegmental nerve tract $(I S N)$. As they exit the CNS, both the RP1 and RP3 axons cross to the segmental nervebranch $b(\mathrm{SNb})$. The RP3 axon innervates the first two ventral longitudinal muscle fibers 7 and 6 , while RP1 extends distally to innervate the third ventral longitudinal muscle fiber 13. $B$, A transverse view showing the point where the two RP growth cones diverge to innervate their respective targets (arrow). The growth cone filopodia grow distally to contact multiple muscle fibers (Chiba et al., 1990; Halpern et al., 1991; Sink and Whitington, 1991b). The RP3 growth cone turns internally to innervate both 7 and 6 , while the RP1 growth cone advances across the width of muscle fiber 6 to innervate muscle fiber 13 (Halpern et al., 1991). The RP axons extend between two layers of muscle fibers, the ventral longitudinal fibers, $7,6,13$, and 12 , and the ventral oblique fibers, $17,16,15,14.2$, and 14.1 . Dorsal is to the top, and all these arrangements are symmetrical along the ventral midline of the animal.

Staging. Embryos were staged according to the morphological criteria of Campos-Ortega and Hartenstein (1985), with each stage being further subdivided by calibration to specific events during midgut development in the intact embryo (Halpern et al., 1991). Embryos were collected with $1 \mathrm{hr}$ egg lays on yeasted apple juice agar plates from population cages and incubated at $18^{\circ} \mathrm{C}$. Late stage 16 , when most of the dye fills in this study were performed, corresponds to an embryo with three midgut lobes and a highly convoluted hindgut, but before the appearance of air-filled trachea. At $25^{\circ} \mathrm{C}$ this would correspond to approximately $15 \mathrm{hr}$ of embryogenesis.

Laser ablation. Single muscle fibers in the whole-mount stage 15 embryos were ablated by focused pulses from a dye laser operating at $440 \mathrm{~nm}$, as described by Cash et al. (1992). The embryos were transferred to food plates and allowed to grow to the third larval stage, when they were dissected for analysis.

Muscle fiber duplications. Wild-type eggs were collected from population cages over a $30 \mathrm{~min}$ interval and were incubated at $18^{\circ} \mathrm{C}$, except 

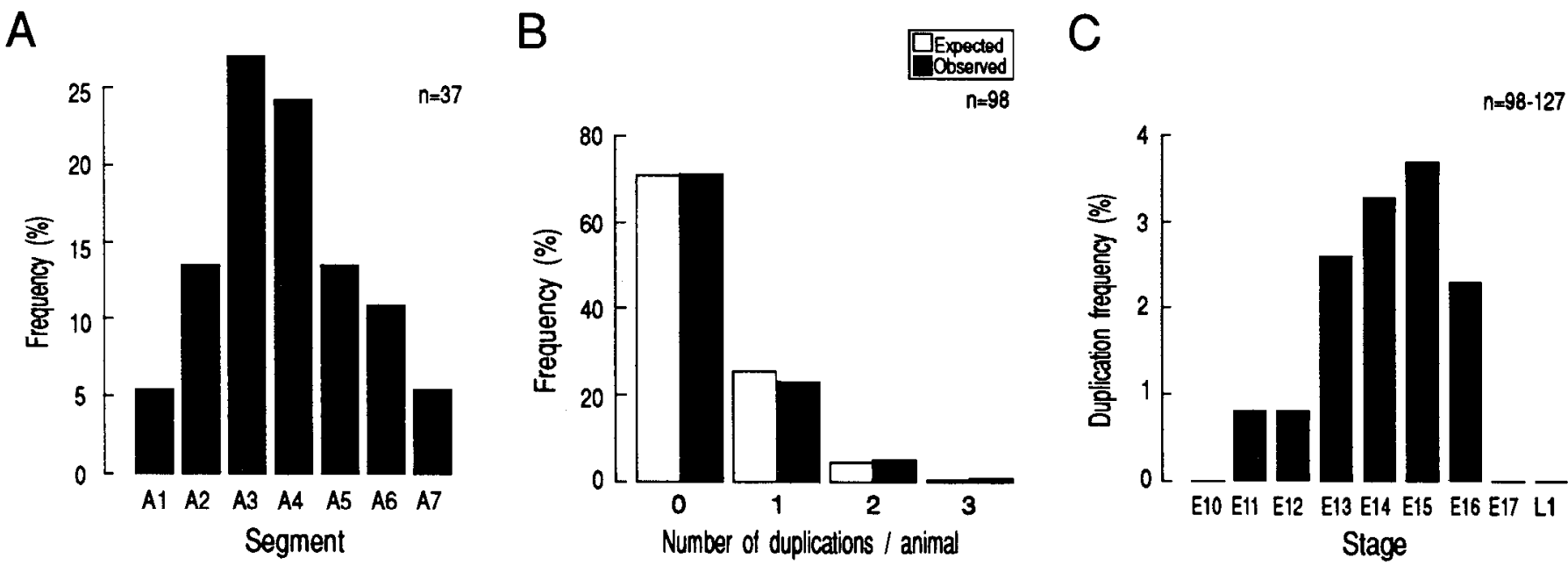

Figure 2. Embryonic heat shock induces the duplication of muscle fiber 13. $A$, Heat shock duplications were most frequent in abdominal segments A3 and A4 ( $n=37$ duplications in 180 larvae). The duplications were generated by several heat shock protocols (see Materials and Methods). $B$, The frequency distribution of muscle fiber 13 duplication, sampled in segments $A 2-A 6$ (mean $=4.1 \% ; n=98$ hemisegments in 10 larvac), is closcly modeled by a Poisson distribution with the same mean value of $4.1 \%$. The correspondence between the expected and observed frequency distributions suggests that each duplication is a random and independent event. $C$, The critical period for inducing muscle fiber 13 duplication falls within embryonic stages $14-15$. A 2 hr heat shock (from $18^{\circ} \mathrm{C}$ to $31^{\circ} \mathrm{C}$ ) was delivered at the onset of the embryonic stages indicated $(n=98-127$ hemisegments assayed in 10-13 larvae for each data set). The critical period overlaps with myogenesis and occurs before synapse formation (Johansen et al., 1989b; Bate, 1990; Halpern et al., 1991; Sink and Whitington, 1991b).

during the period of the heat shock. On the basis of the experiments described below, we adopted a standard heat shock protocol of a $2 \mathrm{hr}$ $31^{\circ} \mathrm{C}$ pulse beginning at the onset of stage 15 . In one series of experiments the same pulse was given at various times between stages 10 and 17 to determine the critical period for the muscle fiber duplication. In another set of experiments, a 10 min heat pulse(s) was given by transferring the eggs on mesh between water baths. Data were collected in the third instar larvae, except for those in which the RP ending morphology was analyzed at late stage 16 immediately following the heat shock.

Following standard heat shock treatment, a duplication of muscle fiber 13 was observed in $4.1 \%$ of the sampled third instar larval hemisegments ( $n=98$ hemisegments in 10 larvae). On average, a single duplication event occurred in every two or three abdominal body-wall preparations examined in this group. A similar rate of duplication was found for stage 16 embryos from the same treatment group ( $n=250$ hemisegments in 30 embryos).

Muscle fiber 13 was more likely to duplicate than other fibers. Muscle fibers 6 and 12 duplicated at approximately $1 \%$ frequency, while neither muscle fiber 7 nor any of the ventral oblique muscle fibers, 17, 16, 15, 14.2, and 14.1, whose positions are shown in Figure $1 B$, duplicated after heat shock ( $n=98$ hemisegments in 10 larvae). The rate of deletion for any of the muscle fibers was equally small ( $1 \%$ or less).

Within the abdominal segments A1-A7, the duplication of muscle fiber 13 occurred most frequently in the middle segments $\mathrm{A} 3$ and $\mathrm{A} 4$ (Fig. 2A). There was no left-right bias for the heat shock sensitivity ( $53 \%$ and $47 \%$, respectively; $n=30$ hemisegments in 19 larvae). The frequency distribution for duplication events was closely modeled by a Poisson distribution (Fig. $2 B$ ). Thus, in a given animal, muscle fiber 13 duplications probably occur as independent events.

The critical period for muscle fiber duplication occurred during stages 14-15, as determined by testing successively later $2 \mathrm{hr}$ heat pulses (Fig. $2 C)$. The critical period for duplication of the other ventral muscle fibers occurred during the same period (data not presented here). The onset of the critical period overlapped with the period of embryonic muscle formation but preceded synaptogenesis on the ventral longitudinal muscle fibers examined in this study (Johansen et al., 1989b; Bate, 1990; Halpern et al., 1991). The heat-shocked animals survived to adulthood at a rate similar to that for untreated animals $(78 \%$ and $85 \%$ for, respectively, heat shock and untreated controls; $n=40$ each). Finally, we noted that temperature shifts rather than high-temperature incubation were responsible for the effect (Table 1). Also, a single $10 \mathrm{~min}$ pulse was effective for generating duplications. Therefore, sudden temperature change during a critical period (stages 14-15) is responsible for inducing muscle fiber duplication.

Immunocytochemistry. Antibody labeling was performed as described by Halpern et al. (1991). A serum antibody to HRP was used as a general label for neurons, as these antibodies recognize all neurons in Drosophila (Jan and Jan, 1982). Specific neurons and/or muscle fibers were labeled using antibodies to fasciclin III (Patel et al., 1987; Snow et al., 1989) and Toll (Hashimoto et al., 1991) and also with monoclonal antibody (mAb) $22 \mathrm{C} 10$ (Fujita et al., 1982). $\beta$-Galactosidase expression in rhomboid ${ }^{l a c t}$ flies was determined using a mouse monoclonal antibody

Table 1. Muscle fiber 13 duplications induced by various heat shock protocols ${ }^{a}$

\begin{tabular}{|c|c|c|c|c|c|c|c|}
\hline & \multicolumn{2}{|c|}{ Constant $t^{b}$} & \multicolumn{2}{|l|}{ Shifts $^{c}$} & \multicolumn{3}{|l|}{ Pulses $^{d}$} \\
\hline & $18^{\circ} \mathrm{C}$ & $31^{\circ} \mathrm{C}$ & Up & Down & $2 \mathrm{hr}$ & $10 \mathrm{~min}$ & $\begin{array}{l}6 \text { times } 10 \\
\text { min }\end{array}$ \\
\hline Duplication frequency & $0.0 \%$ & $0.0 \%$ & $1.8 \%$ & $2.0 \%$ & $4.1 \%$ & $2.8 \%$ & $5.8 \%$ \\
\hline Hemisegments (larvae) examined & $109(12)$ & $120(12)$ & $109(12)$ & $99(11)$ & $98(10)$ & $108(12)$ & $104(11)$ \\
\hline
\end{tabular}

\footnotetext{
${ }^{a}$ Data from abdominal A2-A6 hemisegments, scored in third instar larvae.

${ }^{b}$ Development was either at a constant $18^{\circ} \mathrm{C}$ for $8 \mathrm{~d}$ or a constant $31^{\circ} \mathrm{C}$ for $4 \mathrm{~d}$. Note that development roughly doubles in speed from $18^{\circ} \mathrm{C}$ to $31^{\circ} \mathrm{C}$.

c Upward shifts were from $18^{\circ} \mathrm{C}$ to $31^{\circ} \mathrm{C}$ at $22 \mathrm{hr}$ of embryogenesis (stage 15 ), followed by a constant $31^{\circ} \mathrm{C}$ for $4 \mathrm{~d}$. Downward shifts were from $31^{\circ} \mathrm{C}$ to $18^{\circ} \mathrm{C}$ at $11 \mathrm{hr}$ of embryonic development (stage 15) followed by a constant $18^{\circ} \mathrm{C}$ for $8 \mathrm{~d}$.

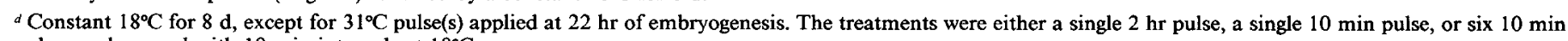
pulses each spaced with $10 \mathrm{~min}$ intervals at $18^{\circ} \mathrm{C}$.
} 

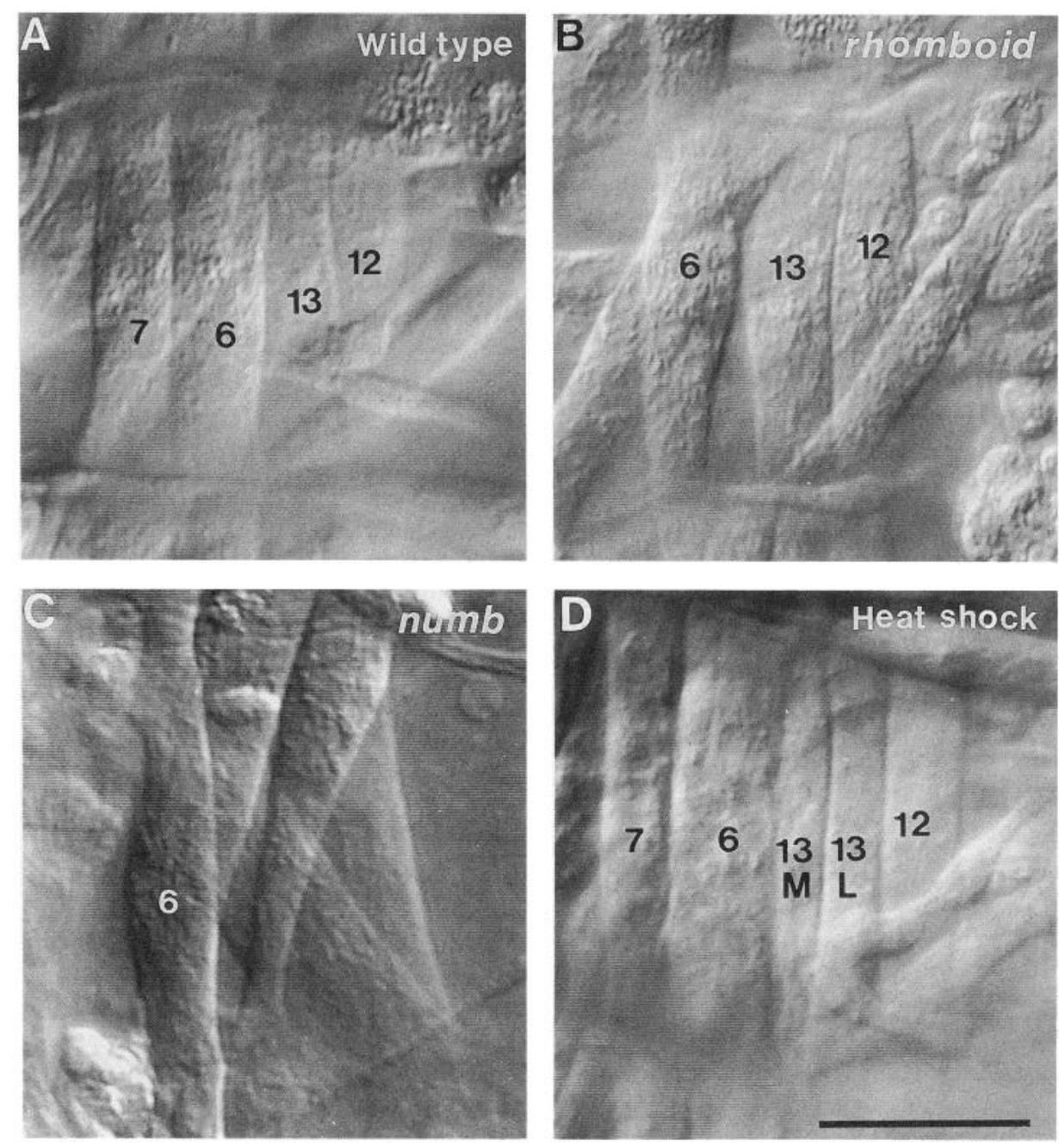

Figure 3. Differential interference contrast images of the ventral longitudinal muscle fibers in right abdominal hemisegments of unfixed control and experimental Drosophila embryonic fillets, viewed at late stage 16 . Anterior is to the top of each of these and all subsequent photographs and tracings. $A$, In a wild-type embryo, four ventral longitudinal muscle fibers, $7,6,13$, and 12 , are present at characteristic positions in each hemisegment. $B$, In the rhomboid mutant, only three of the four ventral longitudinal muscle fibers are present. $C$, The numb mutant had only one longitudinal muscle fiber per hemisegment. The ventral oblique muscle fibers are located directly beneath the single longitudinal muscle fiber provisionally identified as 6 . $D$, Heat shock occasionally induced muscle fiber 13 duplication. The two muscle fibers $13 \mathrm{M}$ (medial) and 13L (lateral) insert at the normal muscle fiber 13 site (compare A). Scale bar, $20 \mu \mathrm{m}$.
(Promega). The Lucifer yellow dye fills were also labeled in some preparations using a rabbit serum (Taghert et al., 1982). The primary antibodies were visualized using peroxidase-labeled avidin-biotin complexes (Vectastain Elite ABC Kit, Vector Laboratories). Muscle fiber nuclei were visualized by incubating with Hoechst 33258 at $0.2 \%$ dilution in PBS (Halpern et al., 1991).

Growth cone visualization in embryos. Unfixed stage 16 embryonic fillets were prepared to expose the CNS and body-wall musculature (Johansen et al., 1989b; Halpern et al., 1991). Single RP motoneurons were identified by their characteristic cell body positions within the CNS. The cell bodies were iontophoretically injected with Lucifer yellow in living preparations maintained in balanced insect saline, and the growth cones of the dye-filled RP motoneurons were visualized using enhanced digital microscopy (Halpern et al., 1991).

\section{Results}

The CNS organization and growth cone behavior of the RP motoneurons in wild-type embryos. Figure 1 illustrates the muscle fibers and motoneurons examined in this study, as they appear in wild-type abdominal hemisegments A2-A7. The four ventral longitudinal muscle fibers $7,6,13$, and 12 are identified by their position, their epidermal insertion sites (Fig. 3A; Crossley, 1978; Anderson et al., 1988; Johansen et al., 1989a,b; Bate, 1990), and their characteristic molecular expression patterns. The muscle fibers 7 and 6 express the membrane proteins Toll (arrow, Fig. 4D; Halfon et al., 1992; Nose et al., 1992) and fasciclin III (arrowhead, Fig. 4F; Halpern et al., 1991) on the surfaces where the muscle fibers contact each other. Fasciclin III, in addition, accumulates heavily at the insertion sites for these muscle fibers. Also, in wild-type muscle fibers there are characteristic numbers of nuclei (Bate, 1990; Budnik et al., 1990; see also Table 2). Each of the ventral longitudinal muscle fibers is innervated by motoneurons projecting from $\mathrm{SNb}$ (Fig. $4 B$; Johansen et al., 1989b).

The motoneurons RP1 and RP3 are individually identified by (1) the characteristic positions of their cell bodies in each abdominal segment of the CNS (Fig. 4A; Thomas et al., 1984; Patel et al., 1987; Jacobs and Goodman, 1989; Halpern et al., 1991; Sink and Whitington, 1991a), (2) their expression of the membrane protein fasciclin III (Fig. $4 E$; Patel et al., 1987; Halpern et al., 1991) and their immunoreactivity to mAb 22C10 (Fig. 4C; Grenningloh et al., 1991), and (3) their characteristic axonal trajectories within the CNS (Fig. 4G; Jacobs and Goodman, 1989; Halpern et al., 1991; Sink and Whitington, 1991a). As noted above, the motoneurons RP1 and RP3 exit the ganglion via the same nerve root and diverge in the vicinity of their targets to innervate separate muscle fibers (Fig. 1B). Dye fills show that in the wild-type embryo RP3 innervates both muscle fibers 7 and 6 with more or less equal-sized branches, while motoneuron RP1 innervates only muscle fiber 13 (Fig. 5A,B). The morphological development of the RP synapses, from their initial growth cone contacts into differentiated motor endings, 

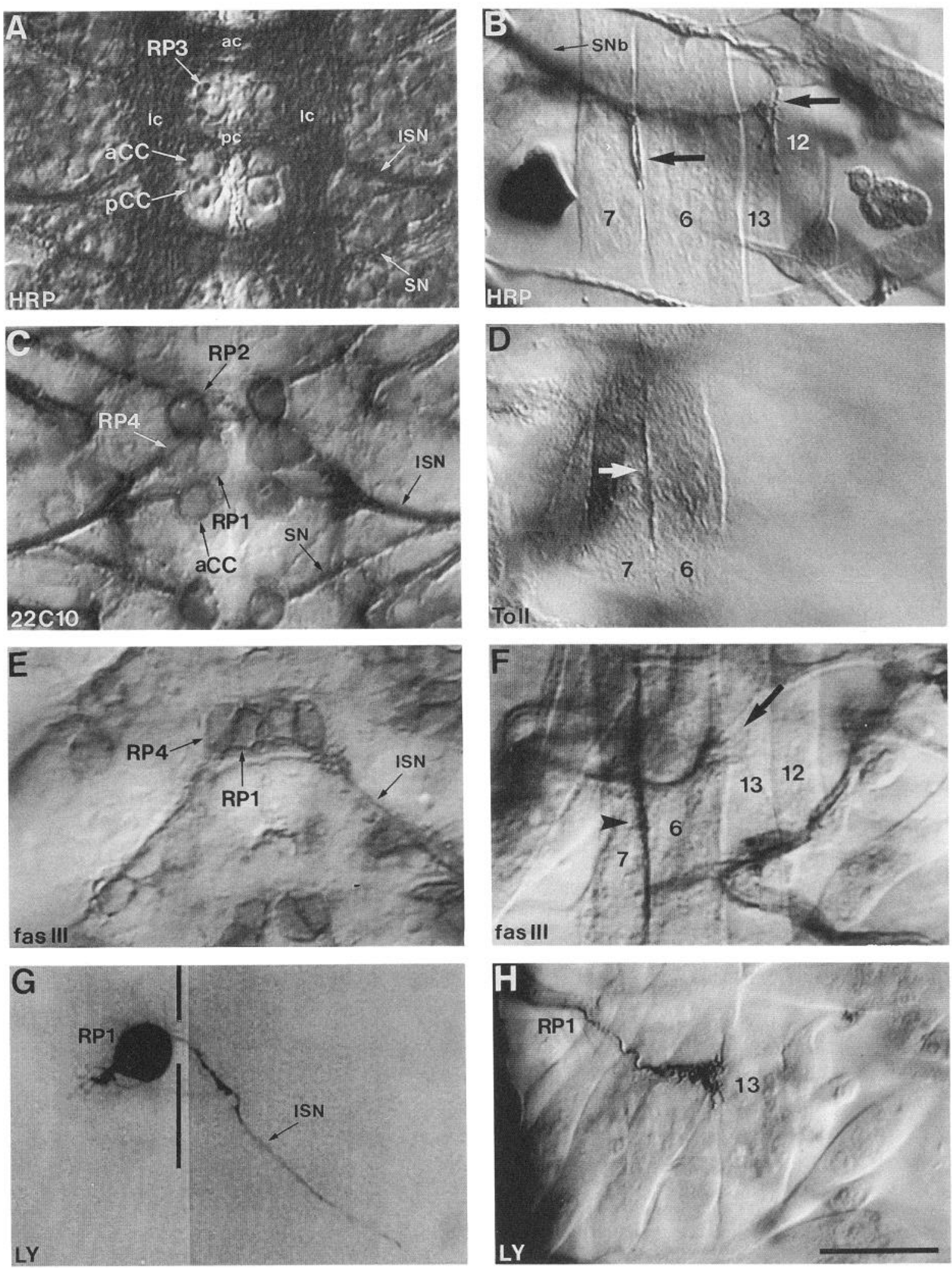

Figure 4. The CNS and ventral longitudinal muscle fibers of wild-type embryos. $A$, The ladder-like arrangement of the major axon tracts within the neuropil of a single CNS segment in a late stage 16 embryo, shown with anti-HRP immunocytochemistry. The motoneuron RP3 is in focus at this level of the ganglion. RP1 lies directly dorsal to RP3, and is out of the optical section (see also Fig. $1 A$ ). $B$, The motoneuronal projections (arrows) to the ventral longitudinal muscle fibers $7,6,13$, and 12 via SNb revealed using anti-HRP labeling. $C$, mAb $22 \mathrm{Cl0}$ labels a subset of neurons within the CNS of a stage 16 embryo, including both RP1 and RP3 (out of optical section), as well as their axons. The antibodies also labels motoneurons RP4, RP2, and aCC. D, The membrane protein Toll accumulates on muscle fibers 7 and 6 in stage 15 , especially at the cleft (arrow), where the two muscle fibers touch each other. E, Fasciclin III immunocytochemistry labels the cell bodies and axons of both RP1 and RP3 (out of optical section) in a stage 16 embryo. RP4 is also labeled. $F$, Fasciclin III expression by a subset of the motoneuron growth cones in 


\begin{tabular}{|c|c|c|c|c|}
\hline $\begin{array}{l}\text { Muscle } \\
\text { fiber }\end{array}$ & $\begin{array}{l}\text { Wild-type }{ }^{b} \\
n=114(22)\end{array}$ & $\begin{array}{l}\text { rhomboid } \\
n=18(4)\end{array}$ & $\begin{array}{l}\text { numbc } \\
n=22(5)\end{array}$ & $\begin{array}{l}\text { Heat shock } \\
n=29(19)\end{array}$ \\
\hline 7 & $8.27 \pm 0.15$ & - & & $8.17 \pm 0.34$ \\
\hline 6 & $13.40 \pm 0.28$ & $9.44 \pm 0.32^{*}$ & - & $12.62 \pm 0.61$ \\
\hline 13 & $9.68 \pm 0.16$ & $9.28 \pm 0.25$ & $\begin{array}{l}9.91 \pm 0.29^{*} \\
-\end{array}$ & $\begin{array}{l}9.00 \pm 0.31(13 \mathrm{M}) \\
8.83 \pm 0.36(13 \mathrm{~L})\end{array}$ \\
\hline 12 & $9.01 \pm 0.14$ & $10.28 \pm 0.23^{*}$ & - & $8.86 \pm 0.34$ \\
\hline
\end{tabular}

$\bar{a}$ The nuclei were visualized by using nucleic acid labeling (see Materials and Methods) and data were collected in A2A6 hemisegments of bodywalls in either third instar larvae ("Wild-type" and "Heat shock") or late stage 16 embryos ("rhomboid" and "numb"). Number in parentheses is number of animals examined.

${ }^{h}$ Similar values were obtaincd for wild-type cmbryos at late stage 16 , as well as for hcat-shocked larvac without muscle fiber duplications (data not shown).

' In both rhomboid and numb mutants, the muscle fiber provisionally identified as 6 had significantly more nuclei than the wild-type muscle fiber 7 but fewer than expected for a wild-type muscle fiber 6 .

${ }^{d}$ With heat shock-induced duplication of muscle fiber 13 , both $13 \mathrm{M}$ and $13 \mathrm{~L}$ each had nuclear numbers very similar to that of single unduplicated muscle fiber $13 \mathrm{~s}$.

*, Significantly differs from the wild-type counterpart (by two-tailed $t$ test at $p<0.01$ level).

was examined in detail by Halpern et al. (1991) and Sink and Whitington (1991b). It was found that by late stage 16 the RP growth cones project to and differentiate at their respective targets. We have therefore examined RP targeting at this and later stages, and where possible, have also examined motor projections in mature larvae.

The rhomboid mutation deleted muscle fiher 7 . The rhomboid gene is involved both early in dorsoventral patterning (Mayer and Nüsslein-Volhard, 1988) and later in CNS development (Klämbt et al., 1990). The gene product is also required for developing sensory organs and muscle fibers (Bier et al., 1990). The homozygous rhomboid embryos have only three ventral longitudinal muscle fibers per abdominal hemisegment, instead of the usual four (Fig. $3 B$ ).

Using morphological criteria, including size, orientation, and location of attachment sites for each of the muscle fibers, we concluded that in the rhomboid mutant, muscle fiber 7 had failed to develop while muscle fibers 6,13 , and 12 remained intact. Consistent with this morphologically based identification, only the most proximal of the three longitudinal muscle fibers, provisionally assigned here as muscle fiber 6 , was immunopositive for both Toll and fasciclin III (Fig. 6D,F). In rhomboid mutants, the fasciclin III and Toll labeling distributed uniformly over the muscle fiber surface, suggesting that their wild-type localization (to the 7-6 cleft; Fig. 4D,F) is due to contact between two muscle fibers expressing the proteins. The nuclear number of the fasciclin III-positive muscle fiber 6 in rhomboid mutants, however, did not correspond to the wild-lype values for either muscle fiber 7 or 6 (Table 2). The rhomboid mutation also affected development of other muscle fibers in dorsal regions of the body wall, as well as the ventral oblique muscle fibers 14.1 and 14.2 (Bier et al., 1990).

Homozygous rhomboid mutants lack several of the midline glia in the CNS. This narrows the distance between the two longitudinal connectives (Klämbt et al., 1990). Despite this change, the RP motoneurons were observed at their characteristic location between the anterior and posterior commissures (Fig. 6A). As in the wild-type, the neurons in the rhomboid mutants were immunopositive for both $22 \mathrm{Cl0}$ (Fig. 6C) and fasciclin III (Fig. 6E). Furthermore, the axon trajectories revealed both by the $22 \mathrm{C} 10$ immunocytochemistry and dye fills were normal (Fig. 6C,G), indicating that the behavior of the RP neurons within the CNS was minimally affected by the mutation. Anti-HRP labeling showed that the developing $\mathrm{SNb}$, which normally contains efferents from the RPs, exited the CNS normally to innervate the ventral longitudinal muscle fibers (Fig. $6 B)$.

RP3 innervated muscle fiber 6 when muscle fiber 7 is absent. We examined the growth cone choices of RP motoneurons in the rhomboid mutants using Lucifer yellow dye fills. In the absence of muscle fiber 7, motoneuron RP3 innervated the remaining muscle fiber 6 in $83 \%$ of embryos examined at late stage $16(n=12$ dye fills in 12 embryos; Fig. $7 A)$. We did not observe collateral branches from the motoneuron on adjacent muscle fibers. In the wild-type embryo, RP3 innervates both muscle fibers 7 and 6 in the cleft (Figs. 1, 5A; Halpern et al., 1991). However, when confronted by a single muscle fiber 6 in the rhomboid mutant, the RP3 axon innervated it from either the proximal or distal side (Fig. $7 A$, left and middle panels). When innervating from the distal side, the axon first extended beneath muscle fiber 6 , turning inward between fibers 6 and 13 (Fig. $7 A$, middle panel).

In $17 \%$ of the dye fills examined, the RP3 growth cone failed to synapse with the remaining muscle fiber 6 , and projected distally toward the dorsal longitudinal muscle fibers. It was not observed to differentiate into a motor ending on alternate muscle fibers during the period examined (Fig. $7 A$, right panel). However, as the mutant embryos do not develop beyond stage 17 (Bier et al., 1990), we cannot rule out the possibility that these RP3 projections would have made synapses at a later time.

SNb, including both RP1 (arrow) and RP3 in stage 16. Also labeled is the membrane contact between muscle fibers 7 and 6 (arrowhead). $G$, An intracellular Lucifer yellow fill of RP1 at stage 16 revealing its axon trajectory within the CNS. The vertical line indicates the midline of the CNS. $H$, A dye-filled RP1 growth cone projecting at an early stage of its contact with the edge of muscle fiber 13 . It has grown past the cleft of muscle fibcrs 7 and 6 (out of optical section). Visualized using anti-Lucifer yellow immunocytochemistry. Abbreviations are as in Figure 1. Scale bar, $20 \mu \mathrm{m}$. 
A $n=38$
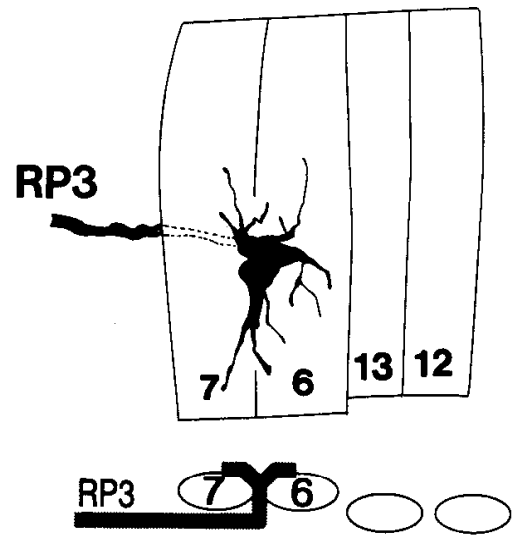

B

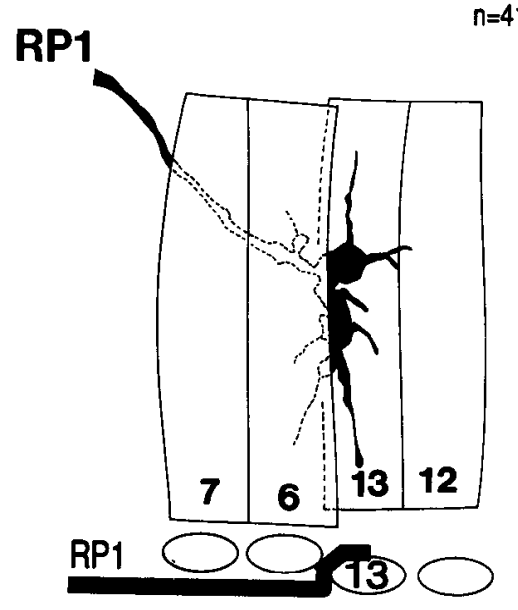

Figure 5. Tracings of Lucifer yellow-filled RP motoneuron growth cones in late stage 16 wild-type embryos. The dotted lines correspond to the portion of the RP growth cone and axon underneath (i.e., external to) the muscle fiber shown. Schematic cross sections indicating the axon trajectories are shown underneath each figure. $A$, The RP3 growth cone innervated muscle fibers 7 and 6 along the cleft. $B$, The RP1 growth cone, by contrast, innervated the single muscle fiber 13 after extending beyond the cleft of muscle fibers 7 and 6 , as depicted by the schematic cross-sectional view. Scale bar, $20 \mu \mathrm{m}$.

RPI innervated muscle fiber 13 normally despite the absence of muscle fiber 7 . The growth cone choices of RP1 were equally informative. Normally the neuron innervates muscle fiber 13 by projecting beneath the first two longitudinal muscle fibers to reach its destination (Fig. $5 B$ ). In the mutant embryo, RP1 invariably innervated muscle fiber 13 despite traversing one fiber fewer to reach it ( $n=13$ dye fills in 13 embryos; Fig. $7 B$ ). Furthermore, the ending morphology resembled the wild-type (Halpern et al., 1991; also compare Figs. 5B, 7B). Thus, the deletion of a muscle fiber proximal to its own target did not cause noticeable errors in the RP1 growth cone behavior.

I.aser ahlation phenocopied the loss of muscle fiher 7 in rhomboid mutants. The rhomboid mutation used in this study is an embryonic lethal and may also have pleiotropic effects. Therefore, we have also deleted muscle fiber 7 in stage 15 embryos by means of laser ablation, and examined the morphology of muscle fiber innervation in mature larvae. Nearly $70 \%$ of the muscle fiber 7-ablated embryos $(n=24)$ developed into the third instar. Each experimental animal had muscle fiber 7 ablated in one to three body-wall hemisegments.

Anti-HRP labeling of all the motor endings in the third instar larvae showed that the remaining muscle fiber 6 was innervated in $95 \%$ of the hemisegments examined $(n=24$ hemisegments in 15 larvae; Fig. $8 B-D$ ). As was observed in the rhomboid embryos (Fig. $7 A$ ), the larval muscle fiber 6 in the laser-operated animals was innervated from cither its proximal or distal sides, with the former more than twice as common as the latter (Fig. $8, B$ and $C$, respectively). Also, at low frequency (8\%), muscle fiber 6 remained uninnervated (Fig. $8 D$ ), consistent with the observation that in a subset of the rhomboid mutant embryos RP3 failed to innervate the remaining muscle fiber 6 (Fig. $7 \mathrm{~A}$, right panel). The larval muscle fiber 6 innervation had wildtype features, such as normal-sized synaptic boutons and branches confined to the muscle fiber edge (A. Chiba and $\mathrm{H}$. Keshishian, unpublished observations). The motor ending morphology on neighboring muscle fibers, such as 13 and 12, was unaltered after the loss of muscle fiber 7 (Fig. $8 B-D$ ). These observations suggest that the RP growth cone choices in the rhomboid mutants were likely due specifically to the absence of muscle fiber 7 , and that the basic pattern of innervation was determined by the initial growth cone behavior.

The numb mutation deleted multiple muscle fibers. The numb mutation disrupts the differentiation of peripheral sensory neurons (Uemura et al., 1989), and in addition results in the loss of several ventral longitudinal muscle fibers. In numb mutant embryos, only one (or occasionally two) of the ventral longitudinal muscle fibers develops (Fig. $3 C$ ). We have provisionally identified the single remaining cell as muscle fiber 6 on the basis of its size, position, and apodeme insertion sites. Furthermore, this muscle fiber was both Toll and fasciclin III immunopositive (Fig. $9 D, F$ ), consistent with either muscle fiber 7 or 6 identity. However, as was observed for the rhomboid mutation, the nuclear number did not correspond to either wild-type value for muscle fiber 7 or 6 (Table 2).

The organization of the CNS neuropil, as judged by anti-HRP, $22 \mathrm{Cl}$, and fasciclin III immunocytochemistry, appeared largely unaltered in the mutant embryos (Fig. 9A,C,E). Also, the apparently normal pathway selected by the RP axons within the CNS suggested that the cellular environment is relatively intact

Figure 6. The CNS and ventral longitudinal muscle fibers of rhomboid mutant embryos. The panels in this figure parallel those of Figure 4, where the corresponding wild-type features are shown. A, Anti-HRP immunocytochemistry in the CNS at late stage 16 showed that both individually identified neurons, including RP3 and RP1 (out of optical section), and the principal axon tracts of the neuropil have developed. The distances between both longitudinal connectives $(l c)$ and between anterior and posterior commissures $(a c$ and $p c$ ) were reduced in comparison to the wildtype (Fig. 4A; Bier et al., 1990; Klämbt et al., 1990). The CNS phenotype of rhomboidlacl used here was less severely affected than that of rhomboid $^{\text {M43 }}$, which Klämbt et al. (1990) characterized. $B$, In the periphery, the motoneuron growth cones, visualized by anti-HRP, innervated the ventral longitudinal muscle fibers 6,13 , and 12. The innervation of muscle fiber 6 in this example was on its distal side (arrow). $C$, mAb $22 \mathrm{C} 10$ revealed 

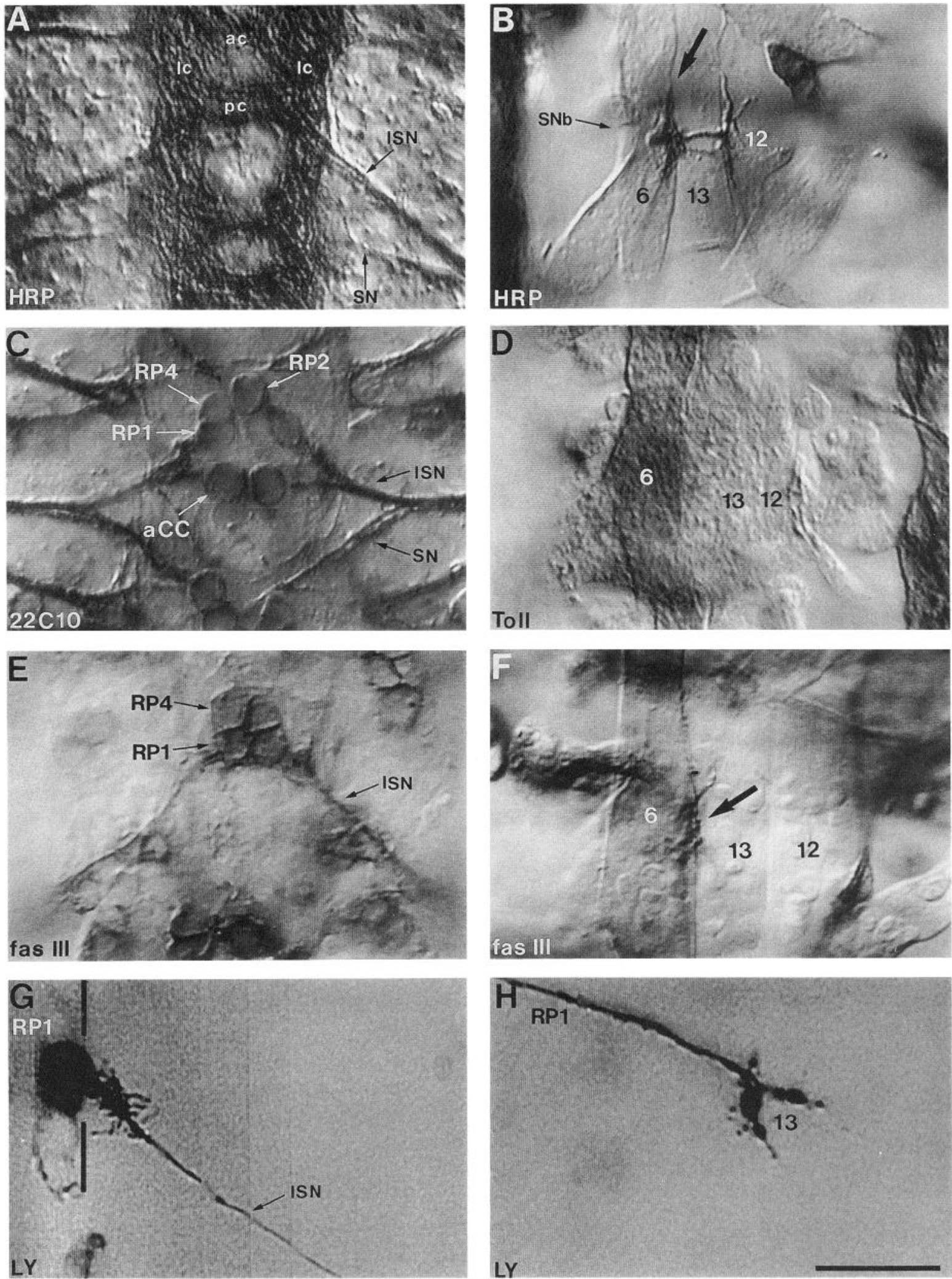

virtually normal neuronal organization in the CNS at stage 16. D, Toll protein accumulated on the membrane surface of muscle fiber 6 at stage 15. The protein was more uniformly spread over the surface, instead of accumulating heavily at the edges as seen in the wild-type (Fig. $4 C$ ). $E$, Fasciclin III immunocytochemistry revealed a normal number of RP motoneurons. The cell bodies were located closer to the midline than in wildtype. $F$, In the periphery fasciclin III immunolabeling was confined to a single muscle fiber (noticeably darker than its neighbors), as well as to the cell's insertion sites. We provisionally identified this cell as muscle fiber 6 . Note that in the absence of a muscle fiber 7 the fasciclin III redistributed uniformly on the muscle fiber (compare Fig. 4E). Muscle fiber 6 was innervated by the fasciclin III-positive motoneurons (presumably RP3, arrow) from its distal side in this example. $G$ and $H$, A Lucifer yellow fill of RP1 shown both within the CNS $(G)$, and in the periphery $(H)$, where it innervated muscle fiber 13 normally (compare Fig. $4 H$ ). Scale bar, $20 \mu \mathrm{m}$. 
Figure 7. Tracings of dye-filled RP motoneuron growth cones in late stage 16 rhomboid mutant embryos. Schematic cross sections indicating the axon trajectories are shown underneath each figure. $A$, The RP3 growth cone in the absence of muscle fiber 7 innervated the remaining muscle fiber 6 using either of two routes (left and middle panels). The growth cone drawn in the middle panel is at a different level than the adjacent muscle fiber 13 (as shown in the cross-sectional view). Occasionally the RP3 motoneuron failed to innervate any muscle fiber and grew distal to muscle fiber 6 (right panel). $B$, The RP1 growth cone, by contrast, innervated muscle fiber 13 without error, despite the loss of muscle fiber 7 . Scale bar, $20 \mu \mathrm{m}$.

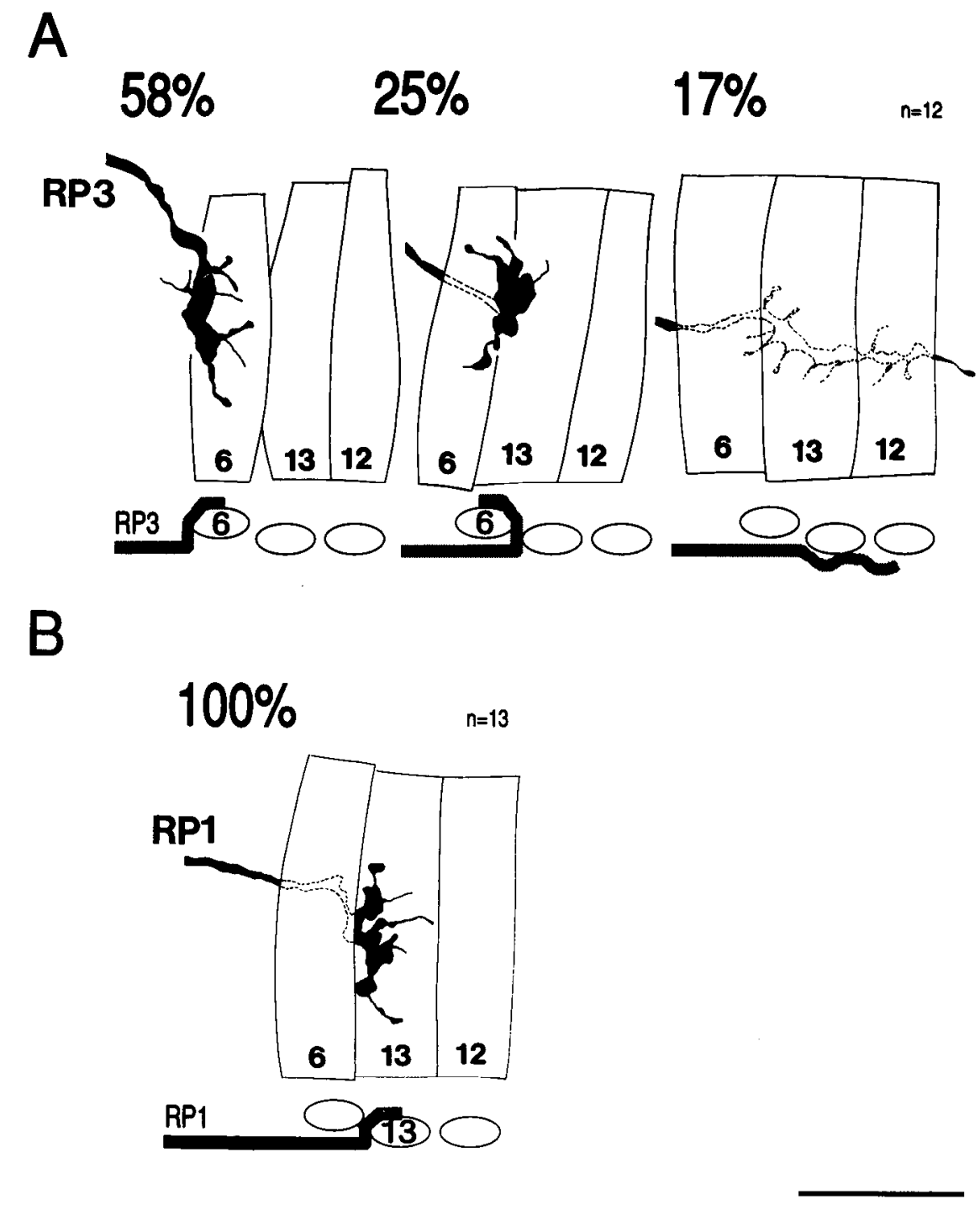

in numb mutant embryos (Fig. 9G). As was observed in the rhomboid mutants, the motoneurons exited the CNS through the correct nerve, with SNb projecting a subset of its axons to the single remaining ventral longitudinal muscle fiber (Fig. 9B).

The numb mutation allowed us to test whether the preference of RP3 for muscle fiber 6 depended on the presence of adjacent muscle fibers. For example, successful target selection might depend on a repulsion from muscle fiber 13, which would halt RP3's distal growth. Furthermore, in the numb mutation RP1 is faced with the complete loss of its muscle fiber target, allowing us to test whether the motoneuron responds by selecting alternate muscle fibers.

RP3's preference for muscle fiber 6 was independent of neighboring muscle fibers. The RP3 dye fills in the late stage 16 numb mutants showed that it innervated the remaining muscle fiber 6 at high frequency (Fig. 10A, left panel). However, the RP3 growth cone occasionally failed to innervate the muscle fiber (Fig. 10 $A$, right panel), a feature also observed for rhomboid mutants. Nevertheless, the preference for muscle fiber 6 was essentially the same both for rhomboid mutants, where muscle fiber 7 was missing but where distal fibers 13 and 12 were intact ( $83 \%, n=12$ dye fills in 12 embryos), and for numb mutants, where muscle fibers 7,13 , and 12 were absent $(86 \%, n=7$ dye fills in 7 embryos; compare Figs. $7 A$, left panel, and $10 A$, left panel). This suggests that the presence or absence of neighboring nontarget muscle fibers had no deciding role in defining RP3 choices.

RPI grew aberrantly in the absence of its target. In contrast to the RP3 growth cone, the RPI growth cone generally did not innervate the remaining ventral longitudinal muscle fiber and instead grew toward the dorsal midline, well beyond the site of its normal destination (Fig. 10B, right panel). We did not detect synaptic contacts by the RP1 growth cone at the distal sites during the period of embryogenesis examined. RP1 grew past muscle fiber 6 in $87 \%$ of the cases ( $n=8$ dye fills in 8 embryos), even though it was the sole available ventral longitudinal muscle fiber. This suggests that the RP1 growth cone retained its relative muscle fiber preferences in the proximal part of its trajectory. The continued distal growth of RPl suggests that contact with its normal target, muscle fiber 13, may be needed to halt its projection. However, we did observe one example of RP1 innervating muscle fiber 6 (Fig. $10 B$, left panel). Since the mutants die before reaching the first instar stage, we were unable to assess the long-term effect of target loss on RP1. However, it is possible 
Control
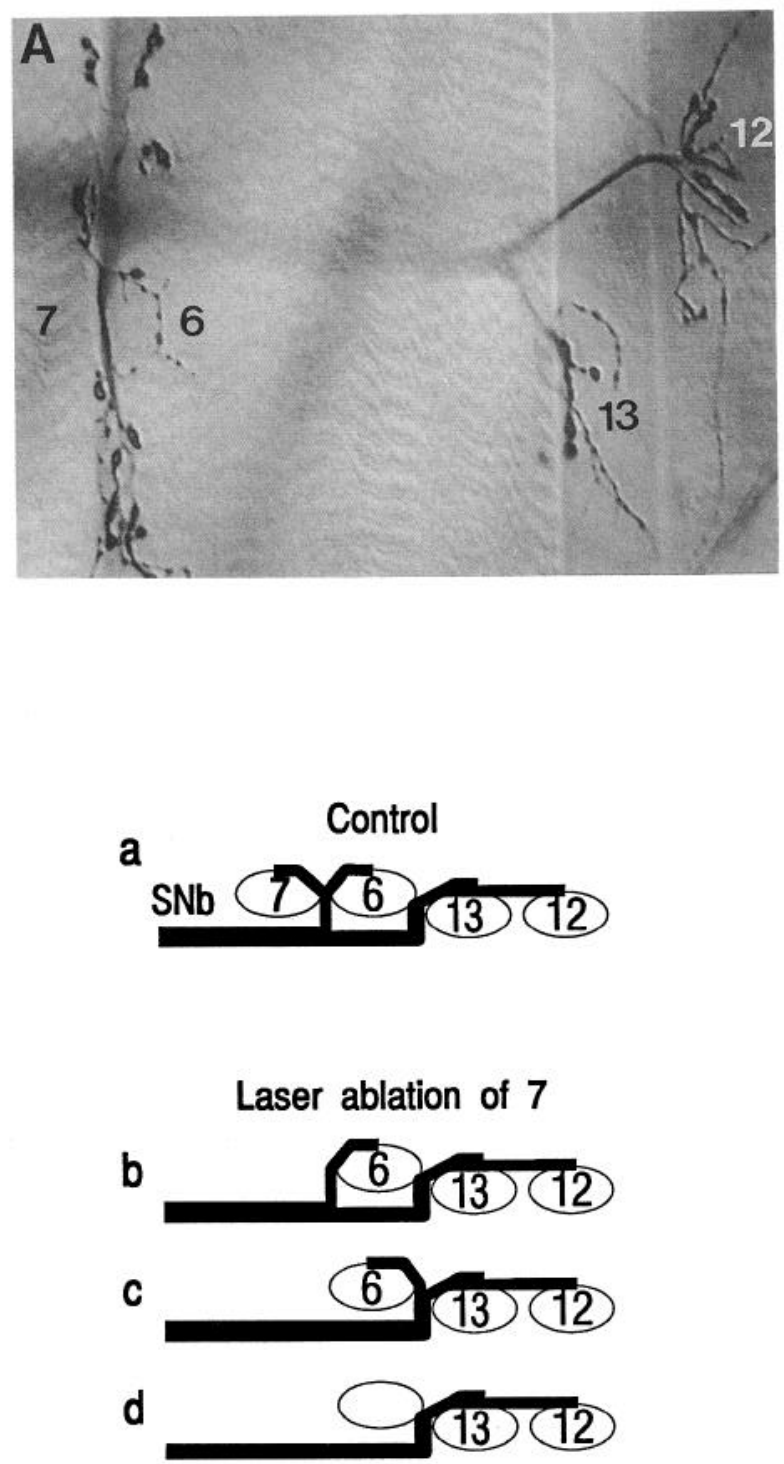

$n=24$

\section{Laser ablation of 7}
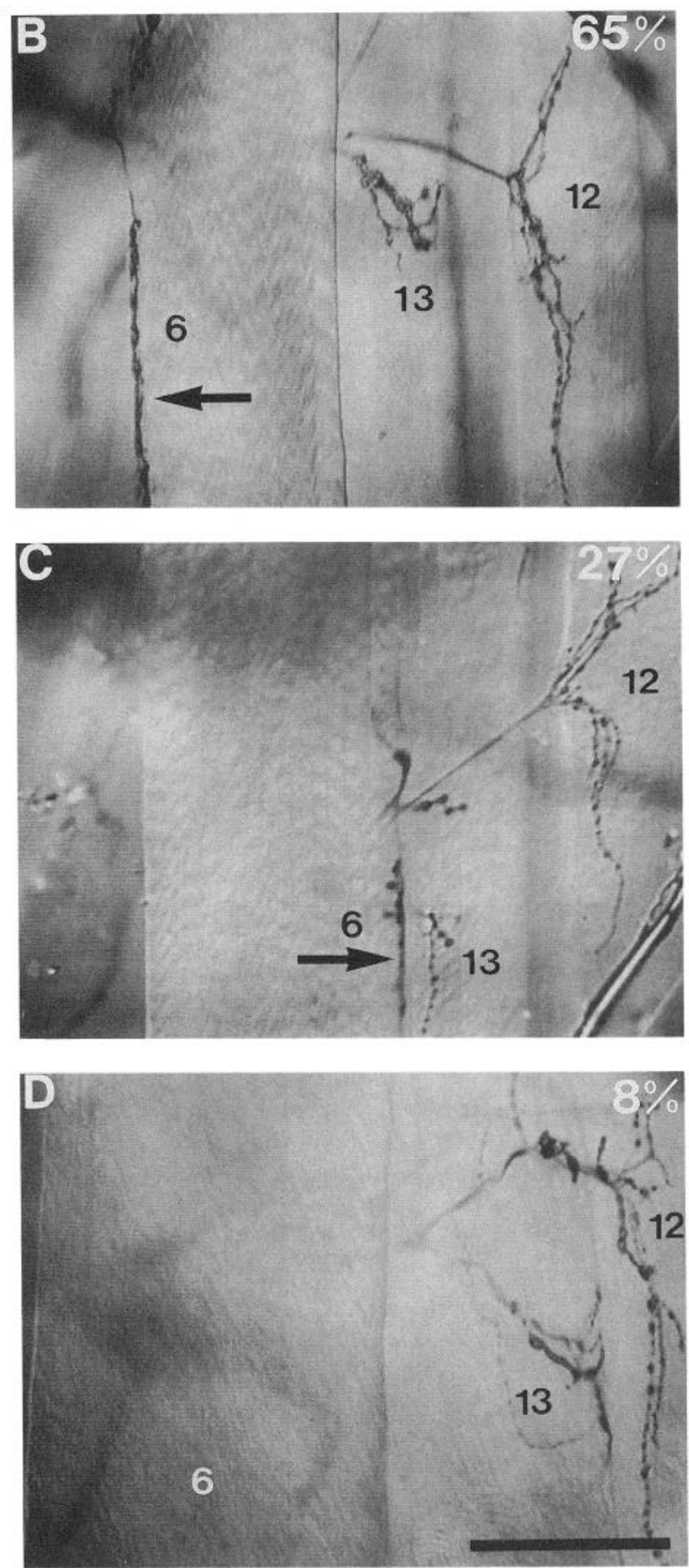

Figure 8. Mature larval innervation patterns following laser ablation of muscle fiber 7 (see Materials and Methods). Following ablation of muscle fiber 7 in whole-mount stage 15 embryos, the animals were allowed to develop to the third larval instar. The ending morphology was examined using anti-HRP immunocytochemistry. A, A wild-type control abdominal hemisegment with an intact muscle fiber 7 . Muscle fibers 7 and 6 are innervated by branches largely restricted to the cleft region. On muscle fiber 13 the motor endings project posteriorly, while on 12 there is generally a multibranched bifurcation (Johansen et al., 1989a; Budnik et al., 1990). B-D, Following the embryonic ablation of muscle fiber 7 , muscle fiber 6 was either innervated on the proximal side $($ arrow, $B)$, innervated on the distal side (arrow, $C$ ), or left uninnervated $(D)$. This was consistent with the embryonic observations with the rhomboid mutants (Fig. 7). The innervation on the neighboring muscle fibers 13 and 12 appeared unaltered. Schematic cross sections $(b-d)$ correspond to each of $(B-D)$ and show the axon trajectory patterns. Scale bar, $50 \mu \mathrm{m}$.

that RP1 would eventually innervate alternative muscle fiber(s), as has been shown for muscle fiber loss elsewhere in the body wall when examined in mature larvae (Cash et al., 1992).

Heat shock occasionally caused the duplication of muscle fiber
13. When wild-type embryos received a brief heat shock during mid-embryogenesis, duplication and deletion of the abdominal body-wall muscle fibers occurred at low frequency (Fig. 2). When incubated at either a constant high or low temperature, the 

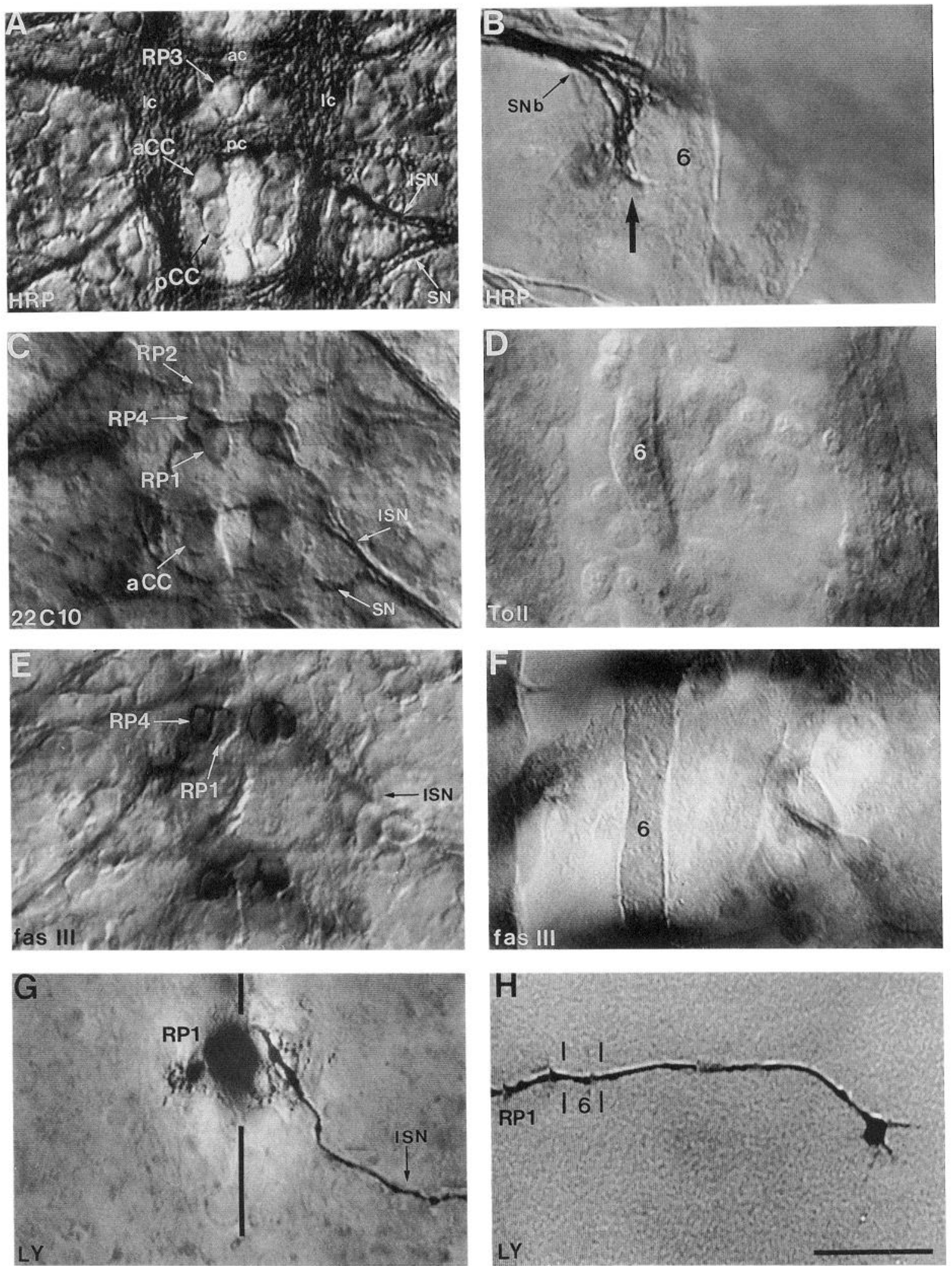

Figure 9. The CNS and ventral longitudinal muscle fibers of numb mutant embryos. The panels in this figure parallel those of Figure 4, where the corresponding wild-type features are shown. $A$, Anti-HRP immunocytochemistry showed virtually normal organization of the major axon tracts within the CNS at stage 16. Cell bodies of RP3 and RP1 (out of optical section) were found in the characteristic positions. B, In the periphery some growth cones innervated the remaining muscle fiber 6 , in this example, from the proximal side (arrow). Other growth cones (out of focus) extended beneath the muscle fiber projecting distally. $C, \mathrm{mAb} 22 \mathrm{C10}$ revealed virtually normal organization within the CNS of a stage 16 mutant embryo. $D$, Anti-Toll antibodies labeled the single longitudinal muscle fiber at stage 15 , consistent with its identity being either muscle fiber 6 or 7 (here provisionally designated as 6). E, Antibodies to fasciclin III labeled a normal set of RP motoneurons, including RP1 and RP3 (out of optical section), within the CNS of stage 16 mutant embryo. $F$, As with the muscle fiber 6 in the rhomboid mutation (Fig. $6 F$ ), the remaining muscle fiber 
muscle fiber duplications in the body wall were absent (Table 1). The most frequent effect was the duplication of muscle fiber 13, first evident prior to innervation by late stage 15 (Fig. $3 D$ ).

The duplicated muscle fibers, termed here $13 \mathrm{M}$ (medial) and 13L (lateral), were identified primarily by their attachment sites, position, orientation, and size (Fig. 3D). As the rate of muscle fiber duplication was low and its occurrence random (Fig. $2 B$; see Materials and Methods), the immediately anterior and posterior segments usually contained the normal number of muscle fibers and therefore provided unambiguous reference points for muscle attachment sites on the embryonic body wall. Also, within the same hemisegment the surrounding unduplicated muscle fibers served as consistent landmarks.

We found that each of the duplicated muscle fibers averaged approximately nine nuclei, similar to the number in control, unduplicated muscle fiber 13s (Table 2). In embryos each of the duplicated muscle fibers had essentially the same width as an unduplicated muscle fiber 13. Muscle fibers 7,6, and 12 in the same hemisegment retained their normal number of nuclei despite the addition of an cxtra muscle fibcr. Thercfore, it is unlikely that the duplication resulted from splitting a fully developed muscle fiber 13 , but rather is likely to involve events prior to the completion of myocyte fusion (Bate, 1990).

Anti-HRP antibodies showed that the principal axon tracts within the CNS of the heat-shocked embryos were indistinguishable from untreated embryos (Fig. 11A). The path followed by the RP neurons along the anterior commissure, longitudinal connective, and the intersegmental nerve tract was normal. The full complement of the dorsal RP motoneurons as well as neurons $\mathrm{aCC}$ and $\mathrm{pCC}$ were present in their characteristic locations and numbers, as judged by both differential interference contrast optics and immunocytochemistry using anti-HRP (Fig. 11A) and anti-fasciclin III (data not shown).

Muscle fiber duplication of 13 had no affect on RP3's innervation of fibers 7 and 6. RP3 normally innervates muscle fibers 7 and 6, which lie proximal to the duplication (Fig. 5A). Muscle fiber 13 duplication had no visible effect on the ability of RP3 to innervate muscle fibers 7 and 6 successfully (Fig. 12A), and did not lure collateral branches from the motoneuron $(n=4$ dye fills in 4 embryos). We also performed double-dye fills to monitor the behavior of both RP3 and RP1 in a hemisegment with a duplication of muscle fiber 13 (Fig. $11 \mathrm{C}$ ). The results suggest that the RP3 growth cone is insensitive to changes in the number and relative positions of nontarget muscle fibers, even when the fibers lie within its filopodial reach.

In addition, the differentiation of RP3's axon terminals was unaffected by the adjacent duplication of muscle fiber 13. In both the control and experimental situations, the RP3 growth cone turned internally at the cleft between muscle fibers 7 and 6 and from that location extended processes posteriorly along the cleft on the internally facing surfaces of the two muscle fibers (comparc Figs. 5A, 12A). Although we did not examine growth cone behavior prior to the embryonic stage 16 , the degree of the synaptic terminal maturation appeared morphologically indistinguishable between the control and experimental situations.
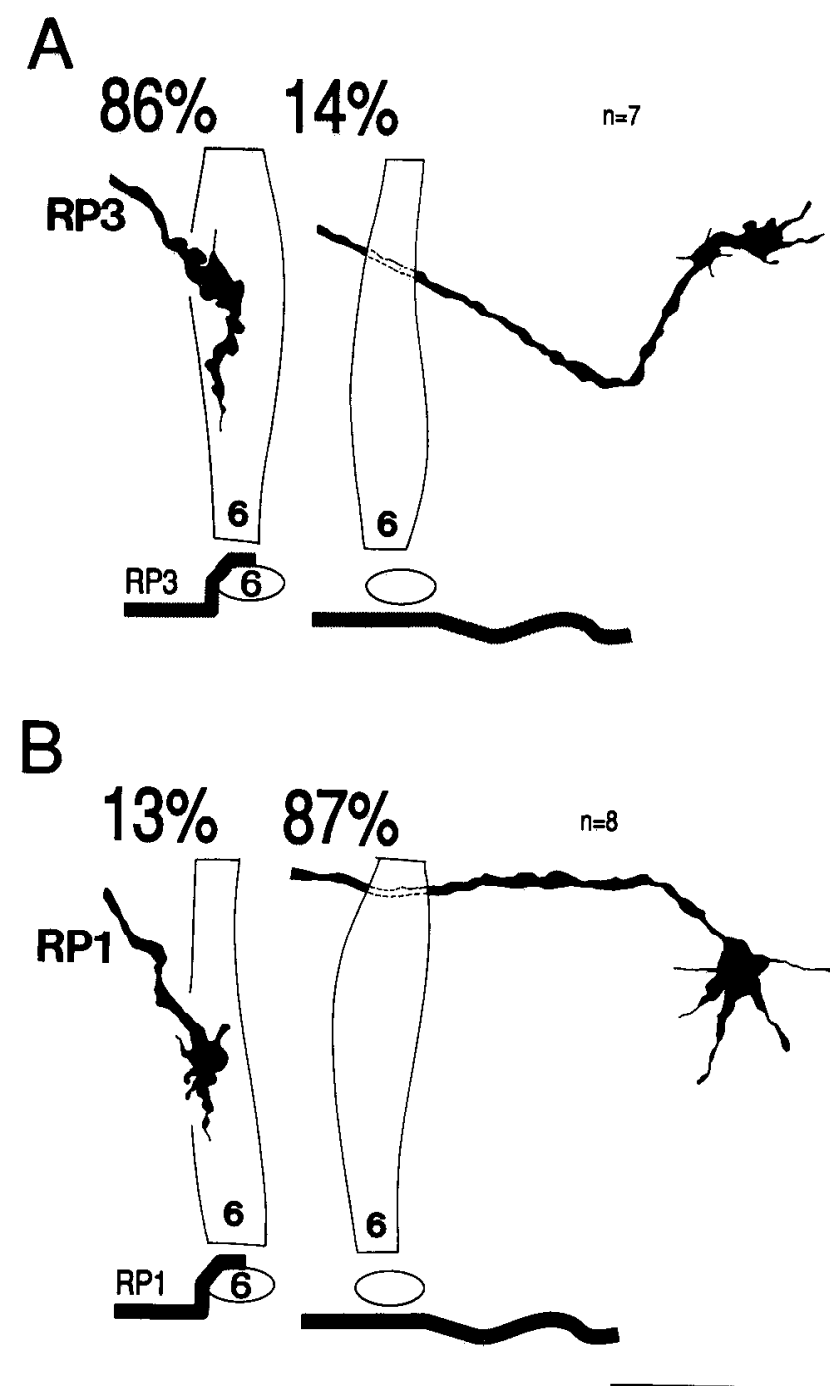

Figure 10. Tracings of dye-filled RP motoneuron growth cones in numb mutant embryos. Schematic cross sections indicating the axon trajectories are shown underneath each figure. $A$, The RP3 growth cone innervated the sole ventral longitudinal muscle fiber with high reliability. The frequency was similar to the previous case for the rhomboid mutants $(86 \%$ vs $83 \%$, where more distal muscle fibers, such as 13 and 12 , were present (Fig. 7A). This suggests that the growth cone's target preference does not depend on neighboring muscle fibers, acting as a backstop. $B$, By contrast, the RPl growth cone, having lost its normal muscle fiber 13 target, usually failed to innervate any muscle fiber during the normal period of synaptogenesis, and instead extended distally beyond the normal stopping point (see Fig. $5 B$ ). However, we observed a single case where the RP1 growth cone innervated muscle fiber 6 (left). Scale bar, $20 \mu \mathrm{m}$.

This lack of effect on muscle fiber 7 and 6 ending anatomy was also observed in third instar larvae with duplicated muscle fiber 13s (see below).

RPI innervated both muscle fiber $13 \mathrm{~s}$. We next examined the response of the RP 1 growth cone to the duplication of its normal targets in the embryos. In all cases examined, RP1 projected to

in numb mutants inserted at sites heavily labeled for fasciclin III. The muscle also showed moderate fasciclin III immunoreactivity. $G$, A Lucifer yellow fill of a single RP1, after being processed with anti-Lucifer yellow immunocytochemistry, showed that the axon trajectory within the CNS was virtually intact. $H$, The growth cone of a dye-filled RP1 that failed to innervate any muscle fiber and projected past the normal stopping point (compare Fig. 4H). Abbreviations are as in Figure 1. Scale bar, $20 \mu \mathrm{m}$. 

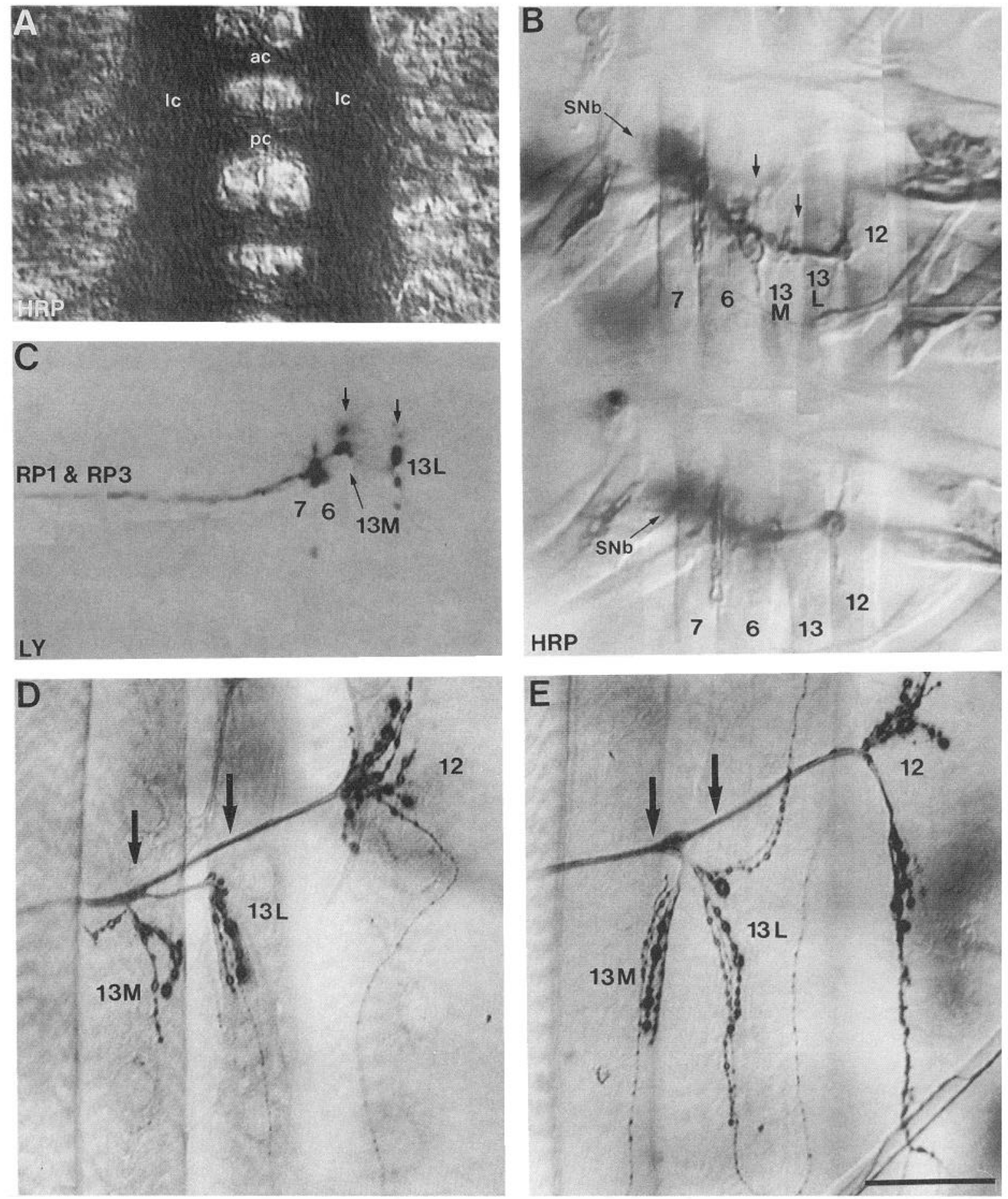

Figure 11. The CNS and the ventral longitudinal muscle fibers of heat-shocked wild-type animals with duplication of muscle fiber 13. $A$ and $B$, Neuron-specific anti-HRP immunocytochemistry of late stage 16 embryos showing the CNS $(A)$ and motoneuron endings $(B)$ at the ventral body wall of two hemisegments, the anterior one bearing a duplication of muscle fiber 13. Despite the extra muscle fiber, all adjacent muscle fibers have received normal innervation. Meanwhile, the duplicated muscle fiber $13 \mathrm{~s}$ were both innervated (arrows). Abbreviations are as in Figure 1 . $C$, In this serial double dye fill, first RP1 and then RP3 was injected with Lucifer yellow at the late embryonic stage 16. This demonstrated that the RP1 growth cone innervated both muscle fibers 13M and 13L (arrows), while the RP3 growth cone (without arrow) innervated muscle fibers 7 and 6 normally. $D$ and $E$, Third instar larval body-wall hemisegments containing duplicated muscle fiber $13 \mathrm{~s}$ were labeled with anti-HRP. Both the duplicated and unduplicated muscle fibers were innervated (arrows). While the neighboring unduplicated muscle fibers showed normal innervation, the innervation of the duplicated muscle fibers showed some variability (see Discussion). Scale bar: $20 \mu \mathrm{m}$ for $A-C ; 50 \mu \mathrm{m}$ for $D$ and $E$. 
both muscle fiber 13 s with equal-sized branches ( $n=5$ dye fills in 5 embryos; Fig. 12B). This indicates that the RP1 motor ending, which is normally confined to a single fiber, can expand to innervate two muscle fibers when presented the duplicated postsynaptic partners.

Although RP1 innervated both muscle fiber $13 \mathrm{~s}$, the axon trajectory was variable. In some cases the RP1 axon turned internally at the cleft between muscle fibers 6 and $13 \mathrm{M}$ and projected over the surface of both duplicated muscle fibers (Fig. $12 \mathrm{~B}$, left panel). This trajectory resembled the normal path taken by RP1 when it innervated a single muscle fiber in control hemisegments (Fig. 5B). However, in nearly half the cases, the RP1 axon grew more distally, turning internally between the two muscle fiber $13 \mathrm{~s}$, and bifurcated at that site to innervate them both (Fig. 12B, right panel).

The innervation of the duplicated muscle fiber $13 \mathrm{~s}$ was confined to the internally facing surfaces of the muscle fibers, as is found for most fibers in the Drosophila body wall (Johansen et al., 1989a,b; Fig. 12B). Once on this surface, the RPl growth cone extended posterior branches along the proximal edges of the muscle fibers, similar to its behavior in controls (Fig. $5 B$ ). Thus, features of the growth cone behavior typical of RP1 remained intact when the motoneuron was challenged with a target duplication.

Larval neuromuscular endings on duplicated muscle fibers. Since the heat-shocked animals survived to adulthood (see Materials and Methods), we were able to examine the body-wall neuromuscular endings in mature larvae. The motor ending morphology in the third instar body wall, as revealcd by antiHRP immunocytochemistry, showed extensive similarities to the embryonic body wall (compare Figs. $11 D, E, 12 B$ ).

Within the hemisegments where muscle fiber 13 was duplicated, both muscle fibers $13 \mathrm{M}$ and $13 \mathrm{~L}$ in larvae were innervated in $93 \%$ of the observed cases ( $n=30$ hemisegments in 19 larvae), a rate similar to that found for embryos (100\%). Furthermore, the pathway variations for the axons innervating the two muscle fiber $13 \mathrm{~s}$ resembled those observed for the RP1 axon in the embryo (Fig. 12B). In general, the larval axons turned either internally at the cleft between muscle fibers 6 and $13 \mathrm{M}$ or, alternatively, projected between muscle fibers $13 \mathrm{M}$ and $13 \mathrm{~L}$ at approximately equal rates (Fig. $11 D, E$; Chiba and Keshishian, unpublished observations). These observations of axonal projections onto duplicated larval muscle fibers, together with those of the laser ablations (Fig. 8), are consistent with the idea that synaptic organization is largely established by the embryonic growth cone choices (Johansen et al., 1989b; Halpern et al., 1991; Cash et al., 1992).

\section{Discussion}

The experiments in this article were designed to test whether Drosophila growth cones can distinguish between individual muscle fibers during synaptogenesis. We found that growth cones retained their target preferences even when the numbers and patterns of muscle fibers were altered (summarized in Fig. 13). The elimination or duplication of a muscle fiber did not lead to a cascade of targeting errors that rippled across the body wall. As long as a muscle fiber remained intact, innervation was accurately made by the appropriate motoneuron, despite alterations of the adjacent musculature. Similarly, doubling or halving of the number of muscle fibers led to an accommodating response by the innervating motoneuron, expanding or restricting its synaptic contacts appropriately. These observations suggest
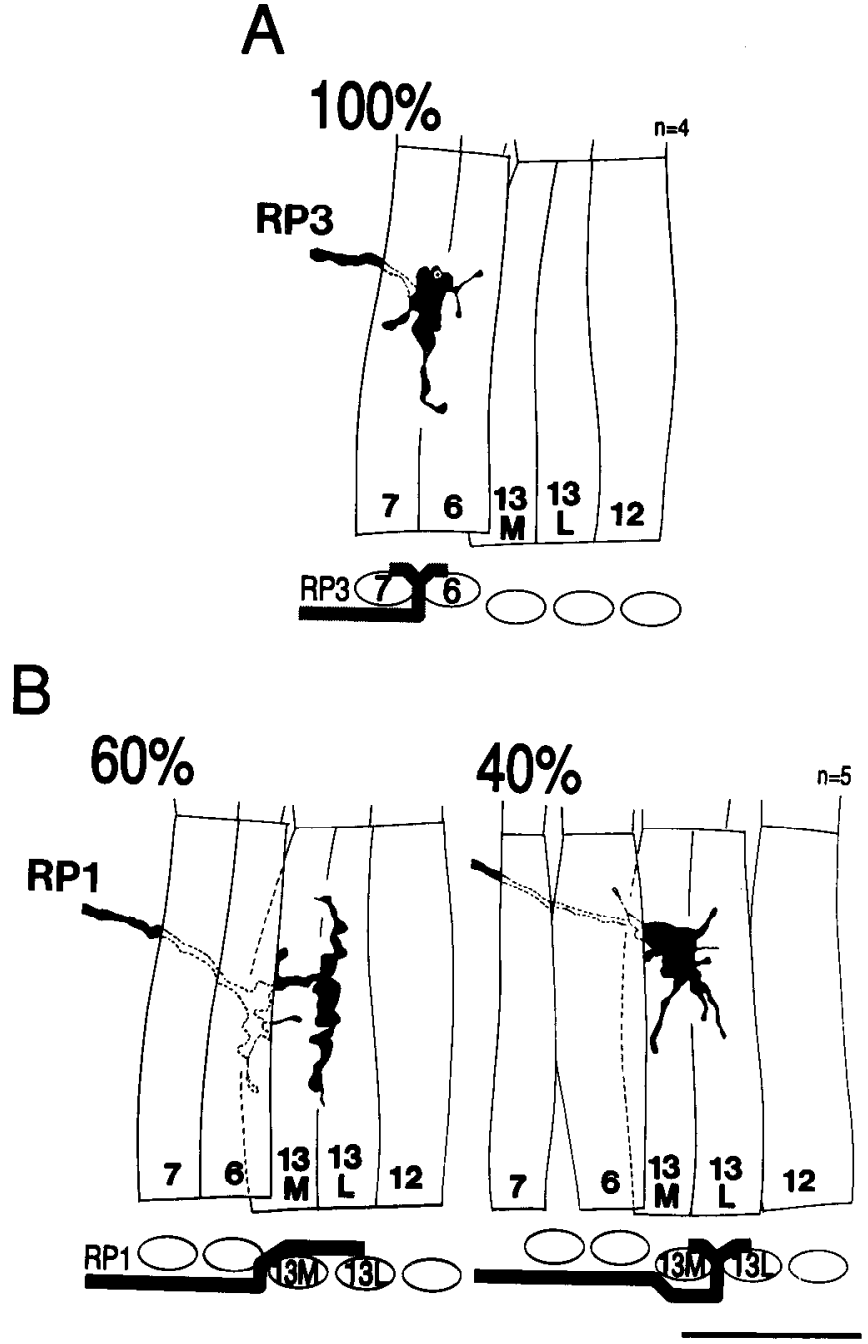

Figure 12. Tracings of Lucifer yellow-filled RP motoneuron growth cones in the late stage 16 wild-type embryos, following heat shockinduced muscle fibcr 13 duplication. Schematic cross sections indicating the axon trajectories are shown underneath each figure. $A$, An RP3 growth cone that has innervated muscle fibers 7 and 6 normally, despite the presence of an extra muscle fiber 13 (compare Fig. 5A). B, An RP1 growth cone that innervated both muscle fibers $13 \mathrm{M}$ and $13 \mathrm{~L}$. Axon trajectories varied when duplicated muscle fibers were innervated; sometimes the axon turned internally at the cleft between muscle fibers 6 and $13 \mathrm{M}$, but in other cases it turned internally at the cleft between the two muscle fiber $13 \mathrm{~s}$. In every case, however, the innervation occurred on the internally facing surfaces of the muscle fibers. Although we observed no case where RP1 growth cone innervated only one of the two muscle fiber $13 \mathrm{~s}$, anti-HRP immunocytochemistry of mature larvae showed that this may occur as a low rate, (Chiba and Keshishian, unpublished observations). Overall, the close resemblance to the larval innervation patterns (Fig. $11 D, E$ ) suggests that the embryonic growth cone choices largely determine the mature ending morphology. Scale bar, $20 \mu \mathrm{m}$.

that motoneuron growth cones respond specifically to their muscle fiber targets and in this fashion sort out their contacts during the early phases of innervation.

In a recent study, Sink and Whitington (1991c) deleted muscle fibers in acutely cultured Drosophila embryonic fillets, examining the behavior of motoneuron RP3. They found that when either muscle fiber 7 or 6 was surgically extirpated with a micropipette, the RP3 growth cone often projected to the remaining muscle fiber. This is consistent with our own observations 

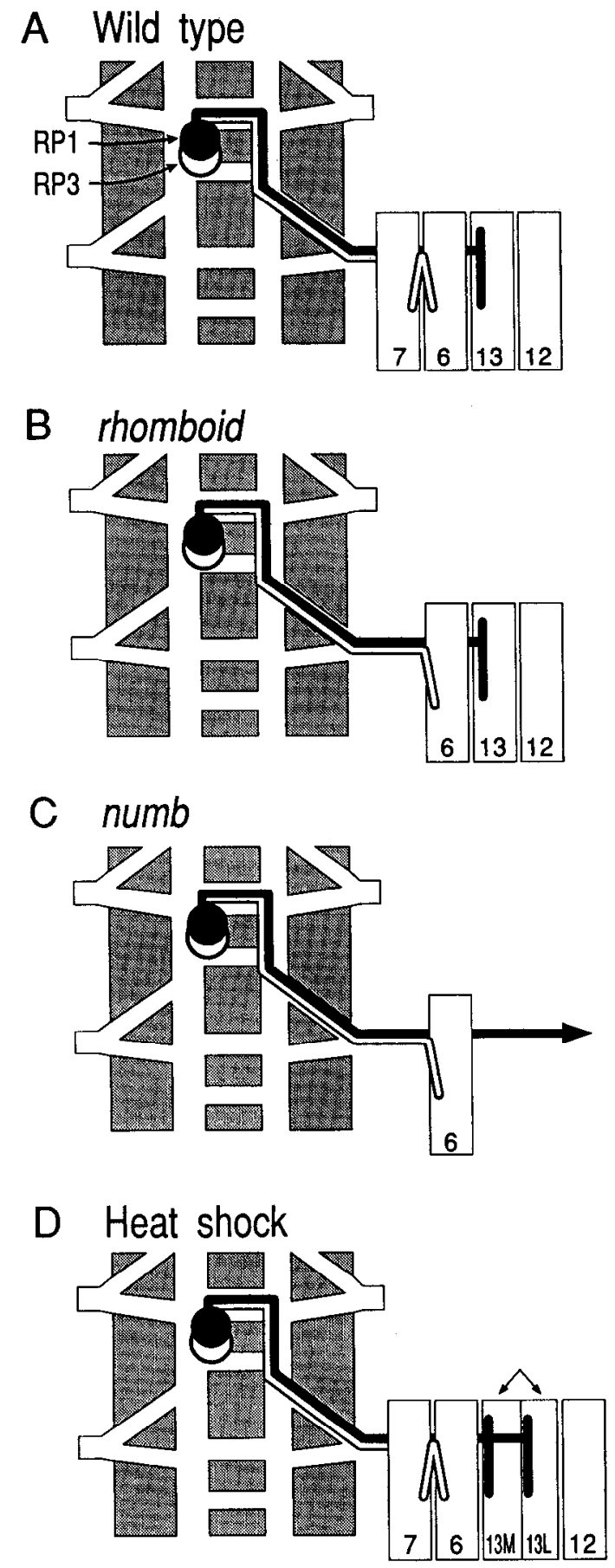

Figure 13. Summary of the target mismatch experiments examined in this article. $A$, In the wild-type (control), individual motoneurons innervated specific muscle fibers, demonstrating precise connectivity. Motoneuron RP3 innervated the two proximal ventral longitudinal muscle fibers 7 and 6, while motoneuron RP1 innervated a single muscle fiber 13 lying immediately distal. Other motoneurons not discussed in this study innervate these same muscle fibers, as well as more distal muscle fiber 12. B, Muscle fiber 7, one of the two normal targets of RP3, was deleted by either the rhomboid mutation or by means of laser ablation. RP3 in the mutant embryos innervated the remaining muscle fiber 6 at high frequency. When it failed to do so, its axon extended distally without innervating any muscle fiber, when examined at the end of stage 16. By contrast, in the same mutants RP1 innervated muscle fiber 13 with high reliability, even though its growth cone crossed one muscle fiber fewer to reach its destination. $C$, The numb mutation alters the muscle fiber pattern more radically. Muscle fibers 7,13 , and 12 were absent, leaving muscle fiber 6 as the only ventral longitudinal muscle using the rhomboid and numb mutants, and the laser ablation of muscle fiber 7 in intact embryos (Fig. 13). Sink and Whitington (1991c), however, noted a differential preference by RP3 for muscle fiber 7 over 6 , a point not directly tested in our study. Furthermore, removal of both fibers led to RP3 projections onto a wide array of alternate muscle fibers. This is comparable to the behavior of RP1 in numb mutants described in this article, as well as the results of Cash et al. (1992), who characterized alternate choices for target deprived motoneurons. Overall, these studies show that growth cones are capable of recognizing single cells as targets despite alteration of the muscle fiber pattern, and that in the complete absence of their preferred targets, motoneurons can project to alternate destinations.

The mismatch experiments described in this article rule out several mechanisms for synaptic connectivity in Drosophila. For example, it is unlikely that the motoneurons select muscle fibers as a function of their relative order within the body wall. According to this scenario RP3 would innervate the first two longitudinal muscle fibers it encountered. In the cases where muscle fiber 7 was missing, as in the rhomboid, numb, and laser experiments (Fig. 13B,C), RP3 never innervated two fibers, but confined its projection to the single remaining muscle fiber 6 . Competition for available muscle fibers is also unlikely as a mechanism for identifying synaptic partners, as we observed normal targeting despite situations where muscle fibers were either duplicated or halved in number.

It is also unlikely that motoneurons identify their targets solely by using nonmuscle cells as guidance cues in the body wall. Normally, motoneuron growth cones contact multiple cell types as they project to their muscle fiber targets (Wang and Keshishian, 1992). However, as they reach their destinations, the growth cone filopodia are usually in contact with multiple muscle fibers (Halpern et al., 1991; Sink and Whitington, 1991a,b; present study). This suggests that the final target selection depends on the ability to respond selectively to the multiple surfaces contacted. This hypothesis is supported by the behavior of RP1 in numb mutants (Fig. 13C). In the absence of its preferred target, the RP1 growth cone continued to project aberrantly toward the dorsal musculature. This suggests that contact with the preferred target is important in halting the growth cone advance.

Muscle fiber patterning in mutant embryos. Two mutations were used in this study that affect the differentiation of embry-

\section{$\leftarrow$}

fiber in each hemisegment. The RP3 growth cone, nevertheless, innervated the remaining muscle fiber 6 with high accuracy. Compared to the previous case where only muscle fiber 7 was absent $(B)$, the target recognition was not degraded by adjacent muscle fiber loss. By contrast, $\mathrm{RP} 1$, having lost its normal target altogether, usually extended beyond its normal stopping point and failed to innervate any muscle fiber, as indicated by the arrow. However, it can innervate muscle fiber 6 at a low rate, demonstrating that the target preference by the motoneuron is not absolute. $D$, When muscle fiber 13 is duplicated (arrows) in heatshocked embryos, the individual motoneurons retain specific target preferences. RP1 replicated its contacts to innervate the duplicated muscle fibers. The two proximal muscle fibers 7 and 6 remain correctly innervated by RP3, while the distal muscle fiber 12 had motor endings of normal morphology (see Fig. 11). This supports the hypothesis that the duplication did not affect the specificity of motoneurons innervating adjacent muscle fibers. These observations show that manipulations of muscle fiber pattern and number have relatively benign effects as long as the preferred muscle fiber target of a motoneuron remains intact in the periphery. 
onic muscle fibers. The role for either the rhomboid or numb product in normal myogenesis remains unknown (Uemura et al., 1989; Bier et al., 1990). The $\beta$-galactosidase reporter associated with the rhomboid ${ }^{\text {lact }}$ insertion is not expressed by bodywall muscle fibers, but rather by midline glia in the CNS and by body-wall epithelial cells, suggesting that the effects on the musculature of the rhomboid mutation are indirect (data not shown). In both mutants there is a single ventral longitudinal muscle fiber that expresses both Toll and fasciclin III, phenotypes typical of both muscle fibers 7 and 6 . We have provisionally identified this cell as muscle fiber 6 on the basis of its insertion sites, orientation, and position. However, molecular probes that distinguish between muscle fibers 7 and 6 are required to confirm this identity, or to rule out that the muscle fiber is a composite of 7 and 6. Nevertheless, motoneurons RP1 and $R P 3$ retained their relative target preferences to the putative muscle fiber 6 . Furthermore, laser ablation of muscle fiber 7 in the embryo led to motor ending development that was consistent with the growth cone choices made in rhomboid and numb inutants.

Effects of target manipulation. We found that motoneuron growth cones sometimes projected aberrantly in the manipulated body walls. Variable axon trajectories occurred when the expected number of target muscle fibers was altered. When muscle fiber 7 was absent (as in the rhomboid mutant, and following laser ablation), the remaining muscle fiber 6 was innervated from either the proximal or distal side, while trajectories to adjacent unaltered muscle fibers were normal (Figs. 7, 8). A similar local effect was observed when muscle fiber 13 was duplicated, where multiple axon trajectories were followed (Figs. $11 D, E ; 12)$. These observations suggest that axonal guidance depends on local cues in the vicinity of the muscle fibers. However, correct synaptic choices were usually made independent of the pathway followed to reach the targets.

We also observed cases where the RP neurons failed to make synaptic connections during the period of embryogenesis examined. These errors occurred when motoneuron targets were either partially or completely removed (Figs. $7 A ; 10 A, D$ ). Ball et al. (1985) described a similar situation following the loss of single muscle pioneers in developing grasshopper limb buds. The coxal depressor motoneuron Df normally targets a single muscle pioneer, but following the ablation of that cell the motoneuron projects to distal regions in the limb bud. Complete removal of the limb bud in grasshopper embryos results in target-deprived motoneurons projecting nonspecifically to alternate body-wall muscles to make functional synapses (Whitington and Seifert, 1984; Whitington, 1985).

In a related study, third instar larvae were examined following the embryonic loss of the oblique muscle fiber 5 (Cash et al., 1992), which is normally innervated by a branch of nerve $\mathrm{SNa}$. The displaced motor endings were located on either of two alternate muscle fibers, on sites approaching the posterior segment border, where SNa terminates. This and the above-mentioned studies in grasshopper suggest that following the elimination of a preferred target, insect motoneurons are capable of innervating alternate muscles. Normally, insect motoneurons project accurately to specific muscle targets during development. Furthermore, as shown in our study, the normal target is preferentially selected by the motoneuron following various alterations of the muscle fiber patterns. Therefore, it is likely that the target muscle fiber exerts an active influence on the exploring motoneuron growth cone, and that in the absence of this signal, the motoneuron's default affinity for other muscle fibers is revealed.

We also note that neuromuscular innervation in Drosophila is robust and resistant to disruption. Muscle fiber alterations have effects largely limited to the innervating motoneurons, leaving the remainder of the peripheral innervation unaltered. We speculate that the existence of primary motoneuron target preferences confers stability to the motor system, reducing the chance of catastrophic innervation errors following changes to the patterning of the musculature.

Cellular recognition during synaptogenesis. The ability of growth cones to respond selectively to single cells is not unique to this systcm. Similar bchavior has also bcen obscrved for the retinular pioneer axons of isogenic Daphnia (Lopresti et al., 1974), the axons projecting within the CNS of the nematode Caenorhabditis elegans (Walthall and Chalfie, 1988; Miller et al., 1992; White et al., 1992), the cercal sensory afferents in crickets (Chiba et al., 1988), and both peripheral and central pioneer axons of grasshopper and Drosophila embryos (Bentley and Caudy, 1983; Keshishian and Bentley, 1983; Palka et al., 1983; Bastiani et al., 1984, 1985; Raper et al., 1984; O'Connor et al., 1990; Grenningloh et al., 1991).

Various synaptic target duplication experiments in insects also support the hypothesis of single-cell recognition. In the moth Manduca sexta, when de novo muscle fibers arise ectopically in the mutant octopod, motoneurons respond by coinnervating both the ectopic muscle fibers and their normal targets (Miles and Booker, 1991). In homeotically transformed adult Drosophila with mutations in the bithorax complex, the descending giant fiber duplicates its mesothoracic arborization in the transformed metathorax, suggesting that the growth cone responds positively to the replicated neuropil generated by homeosis, to innervate duplicated synaptic partners (Thomas and Wyman, 1984).

The active recognition of single cells by growth cones has also been observed in a variety of vertebrate embryos. In the spinal cord of the fish medaka, longitudinal axons specifically contact the segmentally repeated Rohon-Beard cells, although these cells do not serve as obligate guideposts (Kuwada, 1986). Also, the inputs made onto Mauthner cells in the brainstem are consistent with single-cell targeting (Kimmel et al., 1990; Leber and Model, 1991). Furthermore, growth cone selectivity is responsible for the primary muscle preferences of motoneurons observed in both zebrafish and chick embryos (Lance-Jones and Landmesser, 1981; Tosney and Landmesser, 1985; Eisen, 1991; Eisen and Pike, 1992; Landmesser, 1992; Pike et al., 1992).

Partially ablated muscles are correctly innervated in the embryonic chick limb (Whitelaw and Hollyday, 1983a,b; Tosney and Landmesser, 1984), indicating that local cues, possibly derived from the muscles, guide the appropriate motor inputs. Furthermore, Whitelaw and Hollyday (1983b) observed correct innervation following parallel muscle duplications. These observations indicate that chick motoneurons retain their target preferences despite mismatch, and are consistent with our own work in Drosophila. By contrast, when muscle masses were serially duplicated in separate segments, Whitelaw and Hollyday (1983b) found that the distal muscles were not innervated by the expected neurons. It is possible that the second, more distal muscle mass is too distant to be detected by the appropriate motoneurons in the embryonic chick limb, which normally make accurate and direct projections to their muscle destinations (Tosney and Landmesser, 1985). By contrast, in Drosophila the 
experimentally duplicated muscle fibers in a hemisegment are each within the filopodial reach of the RP growth cones.

Molecular mechanisms for target recognition. In general, following expcrimental mismatch, ncurons attempt to innervatc their normal targets. This suggests that in both vertebrate and invertebrate systems growth cones have intrinsic synaptic preferences (Langley, 1895; Grinnell and Herrera, 1981; LanceJones and Landmesser, 1981; Purves et al., 1981; Landmesser, 1992). It is not known whether chemoaffinity is responsible for the accuracy of synaptic connectivity seen in Drosophila, but this is an attractive hypothesis. However, not all the phenomena of synaptic development can be explained by a model based solely on primary target preferences (Prestige and Willshaw, 1976), and recognition is often accompanied by refining mechanisms that may be activity dependent (Meyer, 1982; Schmidt and Edwards, 1983; Reh and Constantine-Paton, 1984; Cline and Constantine-Paton, 1989; Fraser and Perkel, 1990). The role of electrical activity in target refinement during Drosophila embryogenesis remains an open question, although changes in electrical activity can regulate the degree of branch arborization in larval motor endings (Budnik et al., 1990).

A mechanism based on growth cone recognition of specific cell-surface molecules has been demonstrated in the Drosophila CNS. In the developing nervous system, the expression of fasciclin II, a glycoprotein belonging to the immunoglobulin superfamily, is required for several axon fascicle recognition events (Grenningloh et al., 1991). It is likely that molecules with similar roles exist for peripheral guidance and synaptogenesis.

There is good evidence that Drosophila muscle fibers are molecularly heterogeneous, differentially expressing putative transcription factors (Dohrmann et al., 1990), as well as a variety of muscle fiber-specific membrane and cell-surface glycoproteins. For example, glycoproteins known to mediate cellular adhesion in vitro (fasciclins I and III: Goodman et al., 1992: Toll: Keith and Gay, 1990; connectin: Nose and Goodman, 1991; Nose et al., 1992) are expressed at specific synaptic contacts during embryogenesis, in some cases by both synaptic partners (Halpern et al., 1991; Nose and Goodman, 1991; Chiba et al., 1992; Halfon et al., 1992; Nose et al., 1992). In addition, enhancer detector lines have been found that reveal genetic loci expressed by specific subsets of muscle fibers (Harkins and Keshishian, 1991; Nose and Goodman, 1991; Hartenstein and Jan, 1992).

Furthermore, cell adhesion molecules may be modified by their degree of glycosylation, and the perturbation of glycosaminoglycans has been shown to disrupt pioneer neuron guidance in insects (Wang and Denburg, 1992). The recent report of polysialic acid (PSA) in Drosophila embryos (Roth et al., 1992) raises the possibility that the adhesivity of cell-surface molecules in that system may be regulated by PSA glycosylation, as occurs for NCAM in vertebrate embryos (Rutishauser et al., 1988). In the embryonic chick limb, the degree of PSA glycosylation of NCAM regulates the defasciculation of motor axons in specific regions of developing muscles, and also modulates the adhesivity of other cell adhesion proteins, such as L1 (Landmesser et al., 1990).

In conclusion, the target mismatch experiments described in this article indicate that motoneuron growth cones respond prefcrentially to specific muscle fibers during the carly phases of synapse formation, and that the growth cones retain these preferences despite alterations in the pattern of the musculature. The observations are consistent with the hypothesis that indi- vidual muscle fibers in the Drosophila embryonic body wall have unique features, which could be involved in target chemoaffinity. Identifying the molecular mechanisms that govern neuromuscular target preferences remains a major challenge. Functional tests involving either genetic disruption or the ectopic expression of candidate molecules will be required to test the existence of molecular recognition during synapse formation in this system.

\section{References}

Anderson MDS, Halpern ME, Keshishian H (1988) Identification of the neuropeptide transmitter proctolin in Drosophila larvae: characterization of muscle fiber-specific neuromuscular endings. J Neurosci 8:242-255

Ball EE, Ho RK, Goodman CS (1985) Development of neuromuscular specificity in the grasshopper embryo: guidance of motoneuron growth cones by muscle pioneers. J Neurosci $5: 1808-1819$.

Bastiani MJ, Raper JA, Goodman CS (1984) Pathfinding by neuronal growth cones in grasshopper embryos. III. Selective affinity of the G growth cone for the P cells within the A/P fascicle. J Neurosci 4:23112328.

Bastiani MJ, Doe CQ, Helfand SL, Goodman CS (1985) Neuronal specificity and growth cone guidance in grasshopper and Drosophila embryos. Trends Neurosci 8:257-266.

Bate M (1990) The embryonic development of larval muscle fibers in Drosophila. Development 110:791-804.

Bentley D, Caudy M (1983) Pioneer axons lose directed growth after selective killing of guidepost cells. Nature 304:62-65.

Bentley D, O'Connor TP (1992) Guidance and steering of peripheral pioneer growth cones in grasshopper embryos. In: The nerve growth cone (Kater SB, Macagno ER, eds), pp 265-282. New York: Raven.

Bernhardt RR, Nguyen N, Kuwada JY (1992) Growth cone guidance by floor plate cells in the spinal cord of zebrafish embryos. Neuron 8:869-882.

Bier E, Vaessin H, Shepherd S, Lee K, McCall K, Barbel S, Ackerman L, Carretto R, Uemura T, Grell E, Jan LY, Jan YN (1989) Searching for pattern and mutation in the Drosophila genome with a P-lacZ vector. Genes Dev 3:1273-1287.

Bier E, Jan LY, Jan YN (1990) rhomboid, a gene required for dorsoventral axis establishment and peripheral nervous system development in Drosophila melanogaster. Genes Dev 4:190-203.

Budnik V, Zhong Y, Wu CF (1990) Morphological plasticity of motor axons in Drosophila mutants with altered excitability. J Neurosci 10: 3754-3768.

Campos-Ortega JA, Hartenstein V (1985) The embryonic development of Drosophila melanogaster. New York: Springer.

Cash S, Chiba A, Keshishian H (1992) Alternate neuromuscular target selection following the loss of single muscle fibers in Drosophila. J Neurosci 12:2051-2064.

Chiba A, Keshishian H (1991) Growth cone choices of Drosophila motoneurons in response to mismatched targets. Soc Neurosci Abstr 17:213.

Chiba A, Shepherd D, Murphey RK (1988) Synaptic rearrangement during postembryonic development in the cricket. Science 240:901905.

Chiba A, Chang T, Halpern M, Keshishian H (1990) Growth cones in Drosophila embryos show stereotypic morphology and behavior. Soc Neurosci Abstr 16:625.

Chiba A, Chang TN, Keshishian H (1992) Double mutation of fasciclin I and fasciclin III causes erroneous growth cone behavior of Drosophila embryonic motoneurons. Soc Neurosci Abstr 18:1273.

Cline HT, Constantine-Paton M (1989) NMDA receptor antagonists disrupt the retinotectal topographic map. Neuron 3:413-426.

Cooley L, Kelley R, Spradling A (1988) Insertional mutagenesis of the Drosophila genome with single P elements. Science 239:11211128.

Crossley CA (1978) The morphology and development of the Drosophila muscular system. In: The genetics and biology of Drosophila, Vol 2b (Ashburner M, Wright TRF, eds), pp 499-560. New York: Academic

Dodd J, Jessell TM (1988) Axon guidance and the patterning of neuronal projections in vertebrates. Science 242:692-699. 
Dohrmann C, Azpiazu N, Frasch M (1990) A new Drosophila homeo box gene is expressed in mesodermal precursor cells of distinct muscle fibers during embryogenesis. Genes Dev 4:2098-2111.

Eisen JS (1991) Determination of primary motoneuron identity in developing zebrafish embryos. Science 252:569-572.

Eisen JS, Pike SH (1992) Pathfinding by the growth cones of primary and secondary motoneurons in the embryonic zebrafish. In: The nerve growth cone (Kater SB, Macagno ER, eds), pp 323-335. New York: Raven.

Fraser SE, Perkel DH (1990) Competitive and positional cues in the patterning of nerve connections. J Neurobiol 21:51-72.

Fujita SC, Zipursky SL, Benzer S, Ferrús A, Shotwell SL (1982) Monoclonal antibodies against the Drosophila nervous system. Proc Natl Acad Sci USA 79:7929-7933.

Goodman CS, Grenningloh G, Bieber AJ (1992) Molecular genetics of neural cell adhesion molecules in Drosophila. In: The nerve growth cone (Kater SB, Macagno ER, eds), pp 283-303. New York: Raven.

Grenningloh G, Rehm EJ, Goodman CS (1991) Genetic analysis of growth cone guidance in Drosophila: fasciclin II functions as a neuronal recognition molecule. Cell 67:45-57.

Grinnell AD, Herrera AA (1981) Specificity and plasticity of neuromuscular connections: long-term regulation of motoneuron function. Prog Neurobiol 17:203-282.

Halfon M, Hashimoto C, Keshishian H (1992) Drosophila embryos mutant for zygotic Toll have altered RP motoneuron numbers and ectopic motor endings. Soc Neurosci Abstr 18:580.

Halpern ME, Chiba A, Johansen J, Keshishian H (1991) Growth cone behavior underlying the development of stereotypic synaptic connections in Drosophila embryos. J Neurosci 11:3227-3238.

Harkins EW, Keshishian H (1991) Cellular and developmental characterization of two enhancer trap lines with expression in specific embryonic Drosophila muscle fibers. Soc Neurosci Abstr 17:214.

Harkins EW, Chiba A, Keshishian H (1992) Molecular heterogeneity of embryonic Drosophila motoneurons and muscles. Soc Neurosci Abstr 18:40.

Hartenstein V, Jan YN (1992) Studying Drosophila embryogenesis with P-lacZ enhancer trap lines. Rouxs Arch Dev Biol 201:194-220.

Hashimoto C, Gerttula S, Anderson KV (1991) Plasma membrane localization of the Toll protein in the syncytial Drosophila embryo: importance of transmembrane signaling for dorsal-ventral pattern formation. Development 111:1021-1028.

Jacobs JR, Goodman CS (1989) Embryonic development of axon pathways in the Drosophila CNS. II. Behavior of pioneer growth cones. J Neurosci 9:2412-2422.

Jan LY, Jan YN (1982) Antibodies to horseradish peroxidase as specific neuronal markers in Drosophila and grasshopper embryos. Proc Natl Acad Sci USA 79:2700-2704.

Johansen J, Halpern ME, Johansen KM, Keshishian H (1989a) Stereotypic morphology of glutamatergic synapses on identified muscle fiber cells of Drosophila larvae. J Neurosci 9:710-725.

Johansen J, Halpern ME, Keshishian H (1989b) Axonal guidance and the development of muscle fiber-specific innervation in Drosophila embryos. J Neurosci 9:4318-4332.

Keith FJ, Gay NY (1990) The Drosophila membrane receptor Toll can function to promote cellular adhesion. EMBO J 9:4299-4306.

Keshishian H, Bentley D (1983) Embryogenesis of peripheral nerve pathways in grasshopper legs. I. The initial nerve pathway to the CNS. Dev Biol 96:89-102.

Keshishian H, Chiba A, Chang TN, Halfon M, Harkins E, Jarecki J, Wang LS, Anderson MD, Cash S, Halpern ME, Johansen J (1993) Cellular mechanisms governing synaptic development in Drosophila melanogaster. $\mathbf{J}$ Neurobiol, in press.

Kimmel CB, Hatta K, Metcalfe WK (1990) Early axonal contacts during development of an identified dendrite in the brain of the zebrafish. Neuron 4:535-545.

Klämbt C, Jacobs JR, Goodman CS (1990) The midline of the Drosophila central nervous system: a model for the genetic analysis of cell fate, cell migration, and growth cone guidance. Cell 64:801-815.

Kuwada J (1986) Cell recognition by neuronal growth cones in a simple vertebrate embryos. Science 233:740-746.

Lance-Jones C, Landmesser L (1981) Pathway selection by embryonic chick motoneurons in an experimentally altered environment. Proc R Soc Lond [Biol] 214:19-52.

Landmesser L, Dahm L, Tang J, Rutishauser U (1990) Polysialic acid as a regulator of intramuscular nerve branching during embryonic development. Neuron 4:655-667.
Landmesser LT (1992) Growth cone guidance in the avian limb: a search for cellular and molecular mechanisms. In: The nerve growth cone (Kater SB, Macagno ER, eds), pp 373-385. New York: Raven.

Langley JN (1895) Note on regeneration of pre-ganglionic fibers of the sympathetic. J Physiol (Lond) 18:280-284.

Leber SM, Model PG (1991) Effect of precocious and delayed afferent arrival on synapse localization on the amphibian Mauthner cell. J Comp Neurol 313:31-44

Lopresti V, Macagno ER, Levinthal C (1974) Structure and development of neuronal connections in isogenic organisms: transient gap junctions between growing optic axons and lamina neuroblasts. Proc Natl Acad Sci USA 71:1098-1102.

Mayer U, Nüsslein-Volhard C (1988) A group of genes required for pattern formation in the ventral ectoderm of the Drosophila embryo. Genes Dev 2:1496-1511.

Meyer RL (1982) Tetrodotoxin blocks the formation of ocular dominance columns in the goldfish. Science 218:589-591.

Miles CI, Booker R (1991) Ectopic muscles and their innervation in octopod, a homeotic mutation of the moth, Manduca sexta. Soc Neurosci Abstr 17:213.

Miller DM, Shen MM, Shamu CE, Bürglin TR, Ruvkun G, Dubois ML, Ghee M, Wilson L (1992) C. elegans unc-4 gene encodes a homeodomain protein that determines the pattern of synaptic input to specific motor neurons. Nature 355:841-845.

Nose A, Goodman CS (1991) Connectin: a surface protein expressed on a subset of motoneuron axons and the target muscles they innervate in Drosophila. Soc Neurosci Abstr 17:742.

Nose A, Mahajan VB, Goodman CS (1992) Connectin: a homophilic cell adhesion molecule on a subset of muscles and motoneurons that innervate them in Drosophila. Cell 70:553-567.

O'Connor TP, Duerr JS, Bentley D (1990) Pioneer growth cone steering decisions mediated by single filopodial contacts in situ. J Neurosci 10:3935-3946.

Palka J, Schubiger M, Ellison RL (1983) The polarity of axon growth in the wings of Drosophila melanogaster. Dev Biol 98:481-492.

Patel NH, Snow PM, Goodman CS (1987) Characterization and cloning of fasciclin III: a glycoprotein expressed on a subset of neurons and axon pathways in Drosophila. Cell 48:975-988.

Pike SH, Melancon EF, Eisen JS (1992) Pathfinding by zebrafish motoneurons in the absence of normal pioneer axons. Development 114: 825-831.

Prestige MC, Willshaw DJ (1975) On a role for competition in the formation of patterned neural connexions. J Exp Biol 190:77-98.

Purves D, Thompson W, Yip JW (1981) Re-innervation of ganglia transplanted to the neck from different levels of the guinea-pig sympathetic chain. J Physiol (Lond) 313:49-63.

Raper JN, Bastiani MJ, Goodman CS (1983) Pathfinding by neuronal growth cones in grasshopper embryos. I. Divergent choices made by the growth cones of sibling neurons. J Neurosci 3:20-30.

Raper JN, Bastiani MJ, Goodman CS (1984) Pathfinding by neuronal growth cones in grasshopper embryos. IV. The effects of ablating the $A$ and $P$ axons upon the behavior of the $G$ growth cone. J Neurosci $4: 2329-2345$

Reh TA, Constantine-Paton M (1984) Eye-specific segregation requires neural activity in three-eyed Rana pipiens. J Neurosci 5:11321143.

Roth J, Kempf A, Reuter G, Schauer R, Gehring WJ (1992) Occurrence of sialic acids in Drosophila melanogaster. Science 256:673675.

Rutishauser U, Acheson A, Hall AK, Mann DM, Sunshine J (1988) The neural cell adhesion molecule (NCAM) as a regulator of cell-cell interactions. Science 240:53-57.

Schachner M (1992) Neural recognition molecules and their influence on cellular functions. In: The nerve growth cone (Kater SB, Macagno ER, eds), pp 237-254. New York: Raven.

Schmidt JT, Edwards DL (1983) Activity sharpens the map during the regeneration of the retinotectal projection in goldfish. Brain Res 269:29-39.

Sink H, Whitington PM (1991a) Location and connectivity of abdominal motoneurons in the embryo and larva of Drosophila melanogaster. J Neurobiol 22:298-311.

Sink H, Whitington PM (1991b) Pathfinding in the central nervous system and periphery by identified embryonic Drosophila motor axons. Development 112:307-316.

Sink H, Whitington PM (1991c) Early ablation of target muscles mod- 
ulates the arborization pattern of an identified embryonic Drosophila motor axon. Development 113:701-707.

Snow PM, Bieber AJ, Goodman CS (1989) Fasciclin III: a novel homophilic adhesion molecule in Drosophila. Cell 59:313-323.

Taghert PH, Bastiani MJ, Ho RK, Goodman CS (1982) Guidance of pioneer growth cones: filopodial contacts and coupling revealed with an antibody to Lucifer yellow. Dev Biol 94:391-399.

Thomas JB, Wyman RJ (1984) Duplicated neural structure in bithorax mutant Drosophila. Dev Biol 102:531-533.

Thomas JB, Bastiani MJ, Bate M, Goodman CS (1984) From grasshopper to Drosophila: a common plan for neuronal development. Nature 310:203-207.

Tosney KW (1992) Growth cone navigation in the proximal environment of the chick embryo. In: The nerve growth cone (Kater SB, Macagno ER, eds), pp 387-403. New York: Raven.

Tosney KW, Landmesser LT (1984) Pattern and specificity of axonal outgrowth following varying degrees of chick limb bud ablation. J Neurosci 4:2518-2527.

Tosney KW, Landmesser LT (1985) Specificity of early motoneuron growth cone outgrowth in the chick embryo. J Neurosci 5:2336-2344.

Uemura T, Shepherd S, Ackerman L, Jan LY, Jan YN (1989) numb, a gene required in determination of cell fate during sensory organ formation in Drosophila embryos. Cell 58:349-360.

Walthall WW, Chalfie M (1988) Cell-cell interactions in the guidance of late-developing neurons in Caenorhabditis elegans. Science 239: 643-645.
Wang L, Denburg JL (1992) A role for proteoglycans in the guidance of a subset of pioneer axons in cultured embryos of the cockroach. Neuron 8:701-714.

Wang LS, Keshishian H (1992) Guidance of motoneuron outgrowth by a series of peripheral cues during development of Drosophila. Soc Neurosci Abstr 18:1273.

White JG, Southgate E, Thomson JN (1992) Mutations in the Caenorhabditis elegans unc-4 gene alter the synaptic input to ventral cord motor neurons. Nature 355:838-841.

Whitelaw V, Hollyday M (1983a) Thigh and calf discrimination in the motor innervation of the chick hindlimb following deletions of limb segments. J Neurosci 3:1199-1215.

Whitelaw V, Hollyday M (1983b) Position-dependent motor innervation of the chick hindlimb following serial and parallel duplications of limb segments. J Neurosci 3:1216-1225.

Whitington PM (1985) Functional connections with foreign muscles made by a target-deprived insect motoneuron. Dev Biol 107:537540.

Whitington PM, Seifert E (1984) Axon growth from limb motoneurons in the locust embryo: the effect of target limb removal on the pattern of axon branching in the periphery. Dev Biol 106:438-449.

Woodard C, Huang T, Sun H, Helfand SL, Carlson J (1989) Genetic analysis of olfactory behavior in Drosophila: a new screen yields the ota mutants. Genetics 123:315-326. 